University of Zurich

Department of Economics

Working Paper Series

ISSN 1664-7041 (print)

ISSN 1664-705X (online)

Working Paper No. 206

\title{
Explaining structural change towards and within the financial sector
}

Josef Falkinger, Sabrina Studer and Yingnan Zhao

October 2015 


\title{
Explaining structural change towards and within the financial sector*
}

\author{
Josef Falkinger $^{\dagger} \quad$ Sabrina Studer ${ }^{\ddagger} \quad$ Yingnan Zhao $^{\S}$
}

October 13, 2015

\begin{abstract}
This paper presents a $3 \times 3$ general equilibrium model of an OLGeconomy with technological uncertainty, heterogeneous agents and quasi-homothetic preferences to analyze structural change between the real and the financial sector as well as within the financial sector. Besides the consumption and investment good two types of financial services are produced. The three factors of production are: Capital, skilled and unskilled labor. Financial services are needed for transforming savings into future consumption possibilities. The financial market provides deposits and an incomplete set of securities. Payoffs of assets are determined by the future profitability of the technologies in which they are invested. We show the channels through which structural change and inequality reinforce each other and show how they simultaneously emerge from rising per-capita income, an increase in skill supply and technical change.
\end{abstract}

Keywords: Structural change, financialization, quasi-homothetic portfolio decision, inequality

JEL classification: $016, J 31, D 90$

*We wish to thank Timo Boppart, Claire Célérier, David Dorn, Peter Egger, Reto Föllmi, Michel Habib, John Hassler, Jean-Charles Rochet, Christoph Winter, Fabrizio Zilibotti and participants in seminars at the University of Zurich, at the Jahrestagung des Vereins für Socialpolitik 2015, the 30th Annual Congress of the European Economic Association (EEA), the 2015 congress of the Swiss Society of Economics and Statistics (SSES), the Zurich Workshop on Economics 2014 in Solothurn and 2015 in Lucerne for helpful discussions and suggestions. Severin Baumann, Kathrin Friedrich and Nathalie Frischknecht provided excellent research assistance.

${ }^{\dagger}$ University of Zurich, Department of Economics, Zürichbergstrasse 14, CH-8032 Zürich. E-mail: josef.falkinger@econ.uzh.ch

¥University of Zurich, Department of Economics, Zürichbergstrasse 14, CH-8032 Zürich.

E-mail: sabrina.studer@econ.uzh.ch

$\S$ University of Zurich, Department of Economics, Zürichbergstrasse 14, CH-8032 Zürich.

E-mail: yingnan.zhao@econ.uzh.ch 


\section{Introduction}

Financialization and inequality are topics that stir up the public debate - among experts as well as outside the scientific community. Discussions about financialization have gained momentum by the financial crisis (Greenwood and Scharfstein, 2013; Philippon and Reshef, 2012, 2013); the inequality debate was brought "in from the cold" (Atkinson, 1997) towards the end of the last century and has reached the center court recently with the Piketty book (Piketty, 2014). This paper argues that the two phenomena are genuinely related to each other. Structural change towards and within the financial sector, as observed over the last three decades, enhances inequality. And rising inequality fosters financialization.

We present our argument in a model that comprises the most basic tools provided by economics for analyzing sectoral structure and distribution. Financialization means two things: The weight of financial business relative to non-financial business increases and the type of financial business changes. From a macroeconomic perspective the first aspect can be summarized as structural change towards the financial sector: The financial sector expands relative to the production sector. We do not approach this question from a monetary or financial aspect like the nominal transaction volume of the financial relative to the real sector. Our perspective is a real economics one: The financial sector employs resources and generates income for the resources employed. That is, there must be some kind of output (service) that is produced, sold and purchased. The relevant measures are therefore employment and income or output shares; the essential component to be modeled are the production function of the financial sector and the demand function for finan- 
cial services. For capturing the second aspect of financialization - the shift from conventional banking type activities to sophisticated modern finance - an appropriate model structure requires to have two separate sub-sectors within the financial sector which differ in their demand and production characteristics. In sum, we have therefore a three sector model - one production sector and two financial sub-sectors.

Inequality requires to have heterogeneous agents which differ in their endowments. In our model we have low-skilled and high-skilled workers. They are mobile between sectors and cost-minimal skill-intensities differ across sectors. As a consequence, the interaction between sectoral structure and inequality comes through the skill premium. The focus on inequality between lowskilled and high-skilled workers is on the one side motivated by the empirical fact that the rise in inequality over the last decades has been driven to a large extent by skill premia and skill composition, as the ample evidence from the skill-bias literature shows (for instance, Machin and Van Reenen (1998); Piketty and Saez (2003)). On the other side, we see it as a first important step, which later might be complemented by elements which focus on the functional distribution of income between workers and capitalists or on rents. There is capital in our model; it must be. After all, financial markets have the purpose to transform, under risk, current resources into future production possibilities. This requires, on the one side, saving decisions and, on the other side, capital investment into revenue bearing inputs to future production. In our model, returns on capital are generated by two different types of technologies (robust and risky) which transform savings into future consumption possibilities.

Structural change can be caused by the supply side: Changing endowments 
or technical change. The huge literature on directed technical change, for instance, has emphasized this channel (Acemoglu, 2002). There is, however, also an important role for the demand side. Although often neglected, income effects are essential for aggregate developments (Boppart, 2014, 2015; Föllmi and Zweimüller, 2008). We account for demand side effects by assuming that agents have quasi-homothetic preferences of the Stone-Geary form. The specific finance aspect enters the demand side of our model through the following channel: Demand for financial services comes from the need to manage portfolios and to finance investments into profitable projects in a way that reflects the preferences of the agents who own the endowments of the economy. Stone-Geary preferences account for the fact that part of the savings is motivated by future subsistence expenditures.

In our model the finance industry correctly assesses risks and productivity of investment projects and earns no rents. This is against popular views; neither does it reflect a common view of the authors of this paper. Actually, there are many sources for imperfections in the financial sector. For instance, prices and payoffs of financial products may be distorted by neglected correlation (Studer, 2015), or insider knowledge and barriers to entry generate rents for financial intermediation. A salient example is the so called finance premium. There is convincing evidence that a finance premium exists (Célérier and Vallée, 2015; Philippon and Reshef, 2007, 2012), that is, the same type of labor earns more in a finance job than in other occupations. Nonetheless, from a methodological point of view, we consider it as important to start with a benchmark model in which distortions are kept at a minimum. Given the firm basis of such a benchmark, one can then be bold in looking at the role of imperfections which certainly exists in reality 
in general and in the financial business in particular. Arguably, rents can be more easily extracted when they go along with the tide rather than against it. So it is important to know if outcome changes are supported by changes in economic fundamentals. Section 7 gives extensions which provide some ideas how distortions affect the comparative-static results of the benchmark model. Moreover, in the quantitative implementation of our model in Section 9, we try to separate the rent component of the expansion of the financial sector, in particular new finance, from the part that is driven by economic fundamentals.

There is a long literature on the impact of financial development on economic growth (Levine, 2005). 1 The causes of financial sector growth and the changing structure of financial activities, which are the topic of this paper, have been less scrutinized. The literature related to our paper in a more narrow sense is rich as far as the empirical side is concerned. In particular, Philippon and his co-authors did pioneering empirical work on financialization. On the theoretical side the situation is quite different. To our knowledge there are only two attempts to explain structural change towards finance in a gen-

\footnotetext{
${ }^{1}$ While the dominant view in this literature was that financial development is positive for growth, a more skeptical view has emerged in the recent past. Gründler and Weitzel (2012) or Law and Singh (2014) provide evidence that more finance is good for growth at low levels of financial development but harmful beyond a certain threshold. Financial sector growth seems to harm in particular skill-intensive (Kneer, 2013) and R\&D intensive (Cecchetti and Kharroubi, 2015) industries. Moreover, negative growth effects are robust if different measures of financialization are used, for instance market capitalization rather than credits (Rousseau and Wachtel, 2011) or the employment share of the financial sector (Capelle-Blancard and Labonne, 2011). Beck et al. (2012) find that in particular the shift from enterprise credits to household credits is detrimental for growth and inequality enhancing.
} 
eral equilibrium framework. Philippon (2014) sketches in his notes a 2x2 model with a real and a financial sector both producing with capital and labor. The financial sector produces intermediation services for households and firms. The focus is on the equilibrium effects of changes in intermediation costs. Improvements in financial intermediation tend to raise real wages but have in general an ambiguous effect on the GDP-share of the financial sector. The GDP-share of finance rises if more firms need intermediation services. Structural change between services for safe assets and services for risky investments or wage inequality are not addressed nor do income effects play a role for the relative size of the financial compared to the real sector. There is only one type of labor, one interest bearing asset and preferences are homothetic. Moreover, there are two types of households - infinitely living saver households and households which live two periods and borrow when young. By contrast, in our paper all households live for two periods and save when young; savings can be invested in a portfolio of safe and risky assets. The second theoretical explanation of structural change towards finance is provided by Gennaioli et al. (2014). Like in Philippon (2014) a 2x2 framework is considered and structural change within the financial is not in the focus of the paper. The real sector produces with capital and labor, the financial sector consists of financial intermediation experts in whom investors trust. Therefore they are willing to pay them fees. Like in our set-up households live two periods and save when young. Moreover, they also account for risky assets. Inequality among households, however, plays no role. The saving decision is exogenous - young households save the entire wage - and the portfolio choice is determined by mean-variance preferences. The main driver for structural change towards finance in their model is the idea that financial intermediation services are not only required for the financing of new capital 
but also for the preservation of the entire stock of capital accumulated over time. Since in a Solow type growth model the capital coefficient increases, the share of financial services in GDP increases, too. In our model, which focuses on comparative-static equilibrium effects of skills and endowments, technologies and preferences, no long-run accumulation effect is considered.

The structure of the paper is as follows. The next section outlines the formal structure of our $3 \times 3$ model and its building blocks. Section 3 analyzes the production equilibrium, Section 4 derives the demand for goods and financial services. Section 5 summarizes the effects of inequality on the sectoral structure of the economy. In Section 6 the general equilibrium is characterized and comparative-static effects are derived analytically. Section 7 gives extensions which provide some ideas how distortions affect the comparativestatic results of the benchmark model. In Section 8 an alternative to the benchmark specification of the model is considered and the robustness of the results is discussed. Section 9 confronts the theoretical results with empirical evidence from the U.S.. Moreover, a calibration exercise is provided. Main conclusions are summarized in the last section.

\section{Model}

\subsection{Model set-up}

We model a 3 sector, 3 factor economy. There is a production sector $X$ and a finance sector $Z$ with two sub-sectors $Z_{1}$ and $Z_{2}$. All sectors employ lowskilled and high-skilled workers. Produced goods are used for consumption 
and investment. For transforming savings into future consumption possibilities, more or less risky technologies are available which use capital as input and deliver consumption goods as output in the next period. (As an extension we present a variant of the model, in which capital is used in the $X$ sector to set up firms.) Financial services have the function to support the transformation of savings into future consumption possibilities. Services $Z_{1}$ are used for safe savings. Services $Z_{2}$ provide state-dependent instruments and are used for savings in securities with risky returns.

We consider a (static) two-period OLG economy. The future $t=1$ is uncertain. It consists of a set $\Theta$ of distinguishable events and a set $\bar{\Theta}$ of events which are indistinguishable in $t=0$. The future state space is $\{\{\theta \mid \theta \in \Theta\}, \bar{\Theta}\}$. We have $\operatorname{prob}(\Theta)=\mu$ and $\operatorname{prob}(\theta \mid \Theta)=\pi_{\theta}$ with $\sum_{\theta \in \Theta} \pi_{\theta}=1.2$ For $\theta \in \Theta$, state-contingent investment possibilities are available which pay off if and only if state $\theta$ is realized. No state-contingent investment possibilities exist for $\bar{\Theta}$ which reflects "true uncertainty".

\subsection{Saving decision and portfolio choice}

There are $N$ agents who live for two periods. They are endowed with a skill level and work as either high-skilled or low-skilled worker when young. The number of low-skilled workers is $\bar{L}$ and the number of high-skilled workers is $\bar{H}$. The efficiency units of labor provided by a high-skilled and a low-skilled agent are given by $b_{H}$ and $b_{L}$, respectively. They are paid a wage per efficiency unit at rate, $w_{l}, l \in\{L, H\}$. Income $y^{l}=w_{l} b_{l}$ can be consumed in $t=0$ or be saved and transformed to tomorrow's consumption possibilities.

\footnotetext{
${ }^{2}$ This structure is taken from Falkinger (2014).
} 
Agents are assumed to have quasi-homothetic preferences of the Stone-Geary form: Beyond a subsistence level to be expended they spend income on the good produced in the $X$-sector 3 They have an instantaneous indirect utility function of the form $\log \left(e_{t}-\bar{e}_{t}\right)$ where $e_{t}$ is the expenditure for good $X$ consumption and $\overline{e_{t}} \geq 0$ is the subsistence expenditure level in time $t$. Intertemporal preferences are assumed to be additive logarithmic with a discount factor $\delta$.

The intertemporal problem consists of two parts: A saving decision and a portfolio choice. On the one hand, agents have to decide how much to expend on consumption, $e_{0}$, and how much to save, $s$. On the other hand, they have to put the saving in an appropriate portfolio of financial products. For this purpose they demand financial services. With the support of these services they decide how much of the saving is put into deposits, $d$, with a safe payoff $r$, and how much into risky state-contingent financial products (Arrow securities), $f_{\theta}$, which pay off $R_{\theta}$ if state $\theta$ is realized and zero otherwise. We assume that all Arrow securities have the same expected payoff. Specifically, there exists $R>0$ so that

$$
R_{\theta}=\frac{R}{\pi_{\theta}}, \quad \theta \in \Theta
$$

For transforming one unit of deposit, one unit of financial services from subsector 1 is needed; and for transforming one unit of Arrow securities, one unit of financial services from sub-sector 2 is required. Therefore, given the portfolio choice, $\{d, f\}$, with $f=\sum_{\theta \in \Theta} f_{\theta}$, agents have to pay a fee

${ }^{3}$ Achury et al. (2012) show that a Stone-Geary type utility function is appropriate for explaining stylized facts of household finance like higher saving rates of households with higher lifetime income or a larger fraction of risky assets in the portfolios of wealthy agents. 
$T=p_{z_{1}} d+p_{z_{2}} f$ to the financial sector, where $p_{z_{1}}$ and $p_{z_{2}}$ are the prices for financial services $Z_{1}$ and $Z_{2}$, respectively 4 Suppose the fee is charged in the first period and agents internalize the fee in their portfolio choice. The expected utility maximization problem of an agent $l$ with income $y^{l}$ is then given by:

$\max _{s^{l},\left\{f_{\theta}^{l}\right\}_{\theta \in \Theta}, d^{l}} \mathbb{E} U=\log \left(e_{0}^{l}-\bar{e}_{0}\right)+\delta\left[\mu \sum_{\theta \in \Theta} \pi_{\theta} \log \left(e_{\theta}^{l}-\bar{e}_{1}\right)+(1-\mu) \log \left(e_{\bar{\Theta}}^{l}-\bar{e}_{1}\right)\right]$ s.t.

$$
\begin{aligned}
& e_{0}^{l}+\left(1+p_{z_{1}}\right) d^{l}+\left(1+p_{z_{2}}\right) \sum_{\theta \in \Theta} f_{\theta}^{l}=y^{l} \\
& e_{\theta}^{l}=\left\{\begin{array}{l}
R_{\theta} f_{\theta}^{l}+r d^{l}, \text { if } \theta \in \Theta \\
r d^{l}, \text { otherwise }
\end{array}\right. \\
& s^{l}=\sum_{\theta \in \Theta} f_{\theta}^{l}+d^{l} .
\end{aligned}
$$

In Section 4 aggregate demand functions for goods and financial services are derived from this program.

\subsection{Production of goods (X-sector)}

Firms in the $X$-sector employ low-skilled and high-skilled labor as input factors in a linear homogeneous production function

$$
X=G^{x}\left(H_{X}, L_{X}\right),
$$

\footnotetext{
${ }^{4}$ Without loss of generality, it was assumed that financial services are measured in units of savings. Without this normalization the cost of financial services per unit of saving would be $\tilde{p}_{z_{i}}=p_{z_{i}} n_{i}$ rather than $p_{z_{i}}$, where $n_{i}$ denotes the units of financial services needed for one unit of saving in deposits $(i=1)$ and securities $(i=2)$, respectively.
} 
where $H_{X}, L_{X}$ denote respective labor employment in the $X$-sector. There is perfect competition with zero-profit prices. This means:

$$
p_{x}=c_{x}\left(w_{H}, w_{L}\right)
$$

where $c_{x}\left(w_{H}, w_{L}\right)$ are the unit costs and $w_{H}, w_{L}$ are the wage rates per efficiency units.

The goods price is taken as numéraire, $p_{x}=1$. Revenue $X$ is distributed to labor as follows:

$$
W_{x}=w_{L} L_{x}+w_{H} H_{x}=G^{x}\left(L_{x}, H_{x}\right),
$$

where $W_{x}$ is total wage earned in the $X$-sector.

Capital is used in technologies which transform savings into future consumption possibilities. Two types of technologies are available: A robust technology, which transforms under any condition (i.e., in $\Theta$ and $\bar{\Theta}$ ) one unit of capital invested today into $r$ units of output tomorrow; furthermore, for $\theta \in \Theta$, a set of risky technologies specialized to $\theta$-contingent environments. One unit of capital invested in technology $\theta$ delivers $R_{\theta}$ units of output if state $\theta \in \Theta$ occurs tomorrow and zero otherwise. Deposits are invested in the robust technology; savings in securities are invested in the respective risky technologies. The smaller the measure $\pi_{\theta}$ of the state to which a risky technology is targeted, the more productive the capital invested in the technology. Equation (11) expresses this relationship between specialization advantage and risk.

The separation of the production of old age consumption goods by capital from the labor based production of the goods consumed and invested in the 
active period of life is convenient from an analytical point of view. Under a more realistic perspective, however, capital is typically a prerequisite for producing with labor. In the extension in Section 7.5, we show that essentially the same payoff structure arises if $X$ is produced under monopolistic competition and capital is needed to set up firms - by robust and risky set-up technologies, respectively. Asset returns are then generated by the operating profits of the firms the set up of which has been financed by the asset.

In almost all of the further analysis only the relative payoff between robust and specialized risky technologies matters. It is given by:

$$
\rho \equiv \frac{r}{R}
$$

The only exception is the discounting of future subsistence expenditure, $\frac{\overline{e_{1}}}{r}$, for which the level of the return on the robust technology matters.

\subsection{Production of financial services ( $Z$-sectors)}

The financial sector $Z$ consists of two sub-sectors, $Z_{1}$ and $Z_{2}$. They provide financial services for transforming savings through safe and risky assets into future consumption possibilities. (The assets are invested in the robust and risky technologies, and households get the generated revenue as return on their investment.) $Z_{i}, i \in\{1,2\}$, is produced with a linear homogeneous production function $G^{z_{i}}($.$) :$

$$
Z_{i}=G^{z_{i}}\left(H_{z_{i}}, L_{z_{i}}\right), \quad i \in\{1,2\}
$$

where $H_{z_{i}}, L_{z_{i}}$ denote employment levels in the $Z_{i}$-sector. 
In reality, fixed costs may play an important role in the provision of financial services. We consider such costs as an extension in Section 7.1 and show how changes in fixed costs affect the equilibrium outcomes of our model.

We assume perfect competition in the $Z$-sectors and have therefore zero-profit prices

$$
p_{z_{i}}=c_{z_{i}}\left(w_{H}, w_{L}\right), \quad i \in\{1,2\}
$$

where $c_{z_{i}}\left(w_{H}, w_{L}\right)$ are the unit costs.

Revenue $p_{z_{i}} Z_{i}, i \in\{1,2\}$, is distributed to labor

$$
W_{z_{i}}=w_{L} L_{z_{i}}+w_{H} H_{z_{i}}=p_{z_{i}} G^{z_{i}}\left(H_{z_{i}}, L_{z_{i}}\right), \quad i \in\{1,2\}
$$

where $W_{z_{i}}$ is total labor income earned in the $Z_{i}$-sector.

As emphasized in the introduction, perfect competition in the $Z$-sector is an ideal benchmark rather than a description of reality. The role of rents is considered in the extension presented in Section 7.2 .

\section{Production equilibrium and supply of goods and financial services}

At the production side, the essential feature we want to address is variation in skill intensities. For an explicit comparative-static analysis we take production functions of the Cobb-Douglas form.

Let, for $j \in\left\{x, z_{1}, z_{2}\right\}, G^{j}$ have Cobb-Douglas form

$$
G^{j}\left(L_{j}, H_{j}\right)=A_{j} L_{j}^{1-\alpha_{j}} H_{j}^{\alpha_{j}}
$$


where $A_{j}$ is total factor productivity and $\alpha_{j}$ is the factor share of high-skilled workers in sector $j ! 5$ Then

$$
a_{j}^{L}=\frac{1}{A_{j} \kappa_{j}^{\alpha_{j}}}, \quad a_{j}^{H}=\frac{\kappa_{j}^{1-\alpha_{j}}}{A_{j}}
$$

are the input coefficients, and cost-minimizing skill-intensities $\kappa_{j} \equiv a_{j}^{H} / a_{j}^{L}$ are given by

$$
\kappa_{j}(\omega)=\frac{\gamma_{j}}{\omega}, \quad \gamma_{j} \equiv \frac{\alpha_{j}}{1-\alpha_{j}},
$$

where $\omega \equiv w_{H} / w_{L}$ is the relative wage per efficiency unit of skilled labor compared to unskilled labor, which reflects the skill premium (per efficiency unit) 6

\subsection{Wages and prices}

We have for variable unit costs in sector $j$ :

$$
c_{j}\left(w_{H}, w_{L}\right)=\frac{w_{L}^{1-\alpha_{j}} w_{H}^{\alpha_{j}}}{A_{j} \Gamma_{j}}, \Gamma_{j} \equiv \alpha_{j}^{\alpha_{j}}\left(1-\alpha_{j}\right)^{1-\alpha_{j}} .
$$

Using (10) and $p_{x}=1$ in the zero-profit price equation (5), we obtain

$$
w_{L}=A_{x} \Gamma_{x} \omega^{-\alpha_{x}}
$$

${ }^{5}$ The magnitudes of the total factor productivities depend on the unit in which financial services are measured. Since financial services are measured in units of savings, $A_{x}<$ $A_{z_{1}} \leq A_{z_{2}}$ is a plausible restriction on total factor productivities. Analytically no such restriction is required for the results.

${ }^{6}$ Note that $\kappa_{j}=\frac{b_{H} \bar{H}_{j}}{b_{L} \bar{L}_{j}}$. According to (9), the inverse labor demand function is $\omega=$ $\left(\gamma_{j} \frac{b_{L}}{b_{H}}\right) \frac{\bar{L}_{j}}{\bar{H}_{j}}$. Thus, we have skill-biased technical change (in the sense of an outward shift of skilled-labor demand relative to unskilled-labor demand) if the output elasticity $\alpha_{j}$ of high-skilled labor rises or if there is low-skilled labor augmenting progress (that is $b_{L} / b_{H}$ rises). It is worth noting that $\alpha_{j}$ is a sector-specific component whereas $b_{L} / b_{H}$ is uniform across sectors. 
and from (7), for $i \in\{1,2\}$,

$$
p_{z_{i}}=\frac{A_{x}}{A_{z_{i}}} \frac{\Gamma_{x}}{\Gamma_{z_{i}}} \omega^{\alpha_{z_{i}}-\alpha_{x}} .
$$

In sum, prices for financial services are related to the skill premium in the following way:

Fact 1. The price of financial services $Z_{i}, p_{z_{i}}$, is an increasing function of $\omega$ if $\alpha_{z_{i}}>\alpha_{x}$. If $\alpha_{z_{i}}=\alpha_{x}$, then $p_{z_{i}}$ is invariant with respect to $\omega$. Moreover, $\alpha_{z_{i}}>\alpha_{x}\left(\alpha_{z_{i}}=\alpha_{x}\right)$ is equivalent to $\kappa_{z_{i}}>\kappa_{x}\left(\kappa_{z_{i}}=\kappa_{x}\right)$.

As known from the Stolper-Samuelson theorem, this fact holds quite generally and is not an artifact of the Cobb-Douglas specification.

In the further analysis we make the following assumption about the factor intensity ranking of the three sectors.

Assumption 1. $\alpha_{z_{2}} \geq \alpha_{z_{1}}$ and $\alpha_{z_{1}} \geq \alpha_{x}$ with at least one inequality holding strictly.

In Section 9 we provide evidence on the sectoral skill intensities. Assumption 11 is consistent with the evidence.

\subsection{Resource constraints}

Total labor endowment in efficiency units is given by

$$
L=b_{L} \bar{L}, \quad H=b_{H} \bar{H},
$$


so that the "skill richness" of the total labor force is

$$
k \equiv \frac{b_{H} \bar{H}}{b_{L} \bar{L}} .
$$

The aggregate resource constraints are:

$$
\begin{aligned}
& a_{x}^{L} X+a_{z_{1}}^{L} Z_{1}+a_{z_{2}}^{L} Z_{2}=b_{L} \bar{L} \\
& a_{x}^{H} X+a_{z_{1}}^{H} Z_{1}+a_{z_{2}}^{H} Z_{2}=b_{H} \bar{H}
\end{aligned}
$$

with $a_{j}^{l}, j \in\left\{x, z_{1}, z_{2}\right\}, l \in\{H, L\}$ being functions of the skill premium $\omega$ defined in (9).

For illuminating the drivers of structural change on the production side it is worth looking, as an intermediary step, separately at the allocation of resources within the financial sector and the resource allocation between financial services and goods production.

We focus first on the allocation within the financial sector. Let total employment (in efficiency units) in the financial sector be given by $L_{z}$ and $H_{z}$, respectively. If $\alpha_{z_{2}}=\alpha_{z_{1}}$, the allocation of $L_{z}$ and $H_{z}$ on $Z_{1}$ and $Z_{2}$ is determined by the demand side only. If $\alpha_{z_{2}}>\alpha_{z_{1}}$, then the resource constraints $a_{z_{1}}^{L} Z_{1}+a_{z_{2}}^{L} Z_{2}=L_{z}$ and $a_{z_{1}}^{H} Z_{1}+a_{z_{2}}^{H} Z_{2}=H_{z}$ solve to:

$$
Z_{1}=\frac{L_{z}\left(\kappa_{z_{2}}-k_{z}\right)}{a_{z_{1}}^{L}\left(\kappa_{z_{2}}-\kappa_{z_{1}}\right)}, \quad Z_{2}=\frac{L_{z}\left(k_{z}-\kappa_{z_{1}}\right)}{a_{z_{2}}^{L}\left(\kappa_{z_{2}}-\kappa_{z_{1}}\right)}
$$

where $k_{z} \equiv \frac{H_{z}}{L_{z}}$ is the "skill richness" of the labor force in the financial sector. This implies for the supply structure within the financial sector:

$$
\frac{Z_{2}}{Z_{1}}=\frac{a_{z_{1}}^{L}}{a_{z_{2}}^{L}} \frac{k_{z}-\kappa_{z_{1}}}{\kappa_{z_{2}}-k_{z}} \equiv \chi\left(\omega, k_{z}\right)
$$

The following result on within sector structural change follows immediately. 
Proposition 1. If $\alpha_{z_{2}}>\alpha_{z_{1}}$, for a given level of employment in the financial sector, an increase in the skill premium or a rise in the skill richness of labor employed in the financial sector shift the supply structure from traditional financial services $Z_{1}$ to new financial services $Z_{2}$.

Proof. According to (91), $\kappa_{z_{2}}>\kappa_{z_{1}}$ if $\alpha_{z_{2}}>\alpha_{z_{1}}$. For $\kappa_{z_{2}}>\kappa_{z_{1}}, \frac{\partial \chi}{\partial \omega}>0$ and $\frac{\partial \chi}{\partial k_{z}}>0$ as known from the Rybczynski analysis.

Moreover, for a given level of the skill richness, $k_{z}$, of labor employed in the financial sector, system (13) can be written in the form

$$
\begin{aligned}
& a_{x}^{L} X+L_{z}=b_{L} \bar{L} \\
& a_{x}^{H} X+k_{z} L_{z}=b_{H} \bar{H}
\end{aligned}
$$

which leads to the following result.

Fact 2. For a given level of skill richness in the financial sector, we have

$$
\frac{L_{z}}{L_{x}}=\frac{k-\kappa_{x}}{k_{z}-k}
$$

Proof. System (16) solves to $L_{x}=b_{L} \bar{L} \frac{k_{z}-k}{k_{z}-\kappa_{x}}, L_{z}=b_{L} \bar{L} \frac{k-\kappa_{x}}{k_{z}-\kappa_{x}}$. Assumption 1 implies $k_{z}>k>k_{x}$.

Thus, for a given skill premium $\omega$ (so that $\kappa_{x}$ is fixed) and a given skill richness $k_{z}$ in the financial sector, employment in the financial sector is ceteris paribus higher in an economy with a large share of skilled labor $k$.

In a general equilibrium, however, employment in the financial sector is determined simultaneously with the allocation of resources to the goods sector. 


\section{Income distribution and aggregate demand}

The demand for financial services comes from the need of agents to transform current savings into future income. For this purpose the asset-holding agents require financial products and expert services from the financial sector which support them by choosing and managing a portfolio of deposits and securities appropriate for their preferences.

The program max $\mathbb{E} U$ subject to (21)-(41) is only well-defined if $e_{0}>\overline{e_{0}}$ and $e_{1}>\overline{e_{1}}$. This requires that

$$
y^{l}=b_{l} w_{l}>\bar{y} \equiv \bar{e}_{0}+\left(1+p_{z_{1}}\right) \frac{\bar{e}_{1}}{r}, \quad l \in\{L, H\}
$$

$\bar{y}$ denotes the present value of future subsistence expenditure in units of today's final output.

Assuming $y^{H} \geq y^{L}$, which is equivalent to $\omega \geq b_{L} / b_{H}, y^{L}>\bar{y}$ is sufficient for (18). The following fact gives a necessary and sufficient condition for $y^{L}>\bar{y}$. The signs below the parameters show the sign of the respective partial derivatives.

Fact 3. There exists a threshold $\omega_{L}^{+}$so that $y^{L}>\bar{y}$ if and only if $\omega<$ $\omega_{L}^{+}\left(\underset{+}{A_{x}, A_{z_{1}}, b_{L}, \overline{e_{0}}}, \frac{\overline{e_{1}}}{r}\right)$.

Proof. Appendix C.

Savings in securities is positive if and only if the following condition holds: 
$\mu R\left(1+p_{z_{1}}\right)>\left(1+p_{z_{2}}\right) r$. The condition can be rewritten in the form

$$
\mu>p \rho, \quad p \equiv \frac{1+p_{z_{2}}}{1+p_{z_{1}}}, \quad \rho \equiv \frac{r}{R} .
$$

$p \rho$ is the relative net payoff (i.e., after correction for costs of financial services) of savings in safe assets compared to savings in risky assets. If the condition is violated, the expected net payoff of risky investment is lower than the net payoff of risk-free investments and all saving is in deposits.

In the next subsection we analyze individual saving and expenditure behavior. Subsection 4.2 deals with aggregate demand.

\subsection{Individual saving and expenditure behavior}

As is derived in Appendix A, under the assumption that inequalities (18) and (19) are satisfied, individual savings in deposits and securities are given by

$$
d^{l}=s_{d} \frac{\delta}{1+\delta} \frac{y^{l}-\bar{y}}{1+p_{z_{1}}}+\frac{\overline{e_{1}}}{r}, \quad l=\{L, H\}
$$

and

$$
f^{l}=s_{f} \frac{\delta}{1+\delta} \frac{y^{l}-\bar{y}}{1+p_{z_{2}}}, \quad f_{\theta}^{l}=\pi_{\theta} f^{l}, \quad \theta \in \Theta, \quad l=\{L, H\}
$$

respectively, with

$$
s_{d}=\frac{1-\mu}{1-p \rho}, \quad s_{f}=\frac{\mu-p \rho}{1-p \rho} .
$$

Apart from the savings for future subsistence expenditure, $\frac{\overline{e_{1}}}{r}$, in form of deposits, the saving level is proportional to the supernumerary budget $y^{l}-$ $\bar{y}$. In real terms, the value of the supernumerary budget, which is relevant as a basis for saving, depends on the price of the financial service charged 
on the particular form of savings $-p_{z_{1}}$ for deposits and $p_{z_{2}}$ for securities. The split of the saving on safe and risky assets is given by the marginal propensities to save in deposits, $s_{d}$, and in securities, $s_{f}$, respectively. The propensity of safe investment increases in the relative net payoff of the safe asset, $p \rho$, and declines with the measure $\mu$ of states covered by securities. The propensity of risky investment reacts in the opposite direction.7 In sum, the two propensities add up to one so that total saving, $s^{l}=d^{l}+f^{l}$, is given by:

$$
s^{l}=\frac{\delta}{1+\delta} \frac{y^{l}-\bar{y}}{1+p_{z_{1}}}\left(s_{d}+\frac{s_{f}}{p}\right)+\frac{\bar{e}_{1}}{r}
$$

If saving in securities is more costly than saving in deposits, $s_{f}$ is discounted by the fee differential $p .8$

In contrast to net savings, gross savings include the fee to be paid for the financial services consumed in support for the transformation of savings into future income. Adding up $\left(1+p_{z_{1}}\right) d^{l}+\left(1+p_{z_{2}}\right) f^{l}$, we have

$$
s^{l}+t^{l}=\frac{\delta}{1+\delta}\left(y^{l}-\bar{y}\right)+\frac{\left(1+p_{z_{1}}\right) \overline{e_{1}}}{r},
$$

where $t^{l}=p_{z_{1}} d^{l}+p_{z_{2}} f^{l}$ denotes the total fee paid by agent $l$.

Current expenditures $e_{0}^{l}=y^{l}-\left(s^{l}+t^{l}\right)$ are thus:

$$
e_{0}^{l}=\frac{1}{1+\delta}\left(y^{l}-\bar{y}\right)+\overline{e_{0}} .
$$

\footnotetext{
${ }^{7}$ For $\overline{e_{0}}=\overline{e_{1}}=0$ and $p_{z_{1}}=p_{z_{2}}=0$, we have $s_{d}=\frac{1-\mu}{1-\rho}$ and $s_{f}=\frac{\mu-\rho}{1-\rho}$. Defining $\bar{R}=\frac{R}{\mu}$ and $\bar{\rho}=\frac{r}{R}$, we can rewrite the two terms in the form $s_{d}=\frac{\bar{R}(1-\mu)}{\bar{R}-r / \mu}$ and $s_{f}=$ $\frac{\mu \bar{R}-r / \mu}{R-r / \mu}$. Thus, with Cobb-Douglas preferences and zero financial intermediation cost, the portfolio choice coincides with the one in Acemoglu and Zilibotti (1997), where the conditional expectation $\bar{R}$ of the productivity of risky technologies is used rather than the unconditional expectation $R$.

${ }^{8}$ If inequality (19) is violated, then saving in securities is unattractive in the first place and we have a corner solution with $s_{f}=0$ and $s_{d}=s=\frac{\delta}{1+\delta} \frac{y-\bar{y}}{1+p_{z_{1}}}+\frac{\overline{e_{1}}}{r}$.
} 
For the discussion of structural change on the demand side, the effect of income on the portfolio structure is of particular importance 9 According to (20) and (21), richer agents invest a larger share of their saving in risky assets than the relatively poorer ones. The reason is that the provision for future subsistence expenditure by safe investments has diminishing weight if people become richer. This means that saving in deposits has the character of a "necessity" and saving in risky securities is a "luxury". Moreover, if present subsistence expenditure is more pressing than future subsistence expenditure, people save a smaller part of their income when they are poor and the saving rate $s / y$ rises when they get richer 10 The following fact summarizes this important implication of our model.

Fact 4. Let $\bar{e}_{0}>0$ or $\bar{e}_{1}>0$.

a) If $\bar{e}_{1}>0$, then $\frac{\partial(f / d)}{\partial y}>0$.

b) For $\bar{e}_{0}>0, \frac{\partial(s / y)}{\partial y}>0$ if and only if $\frac{\delta \bar{e}_{0}}{1+p_{z_{1}}}>\frac{\bar{e}_{1}}{r}\left[\frac{1+\delta}{s_{d}+s_{f} / p}-\delta\right]$. (Note that ${ }^{9}$ Boppart (2015) analyzes the skill-content of the consumption basket of different income groups. With rising income, a household's demand shifts towards skill-intensive sectors (including financial services; also shown by Suellow (2015) in detail).

${ }^{10}$ The role of subsistence requirements for the saving behavior may call into mind the effects of fixed costs in the model of Greenwood and Jovanovid (1990), where saving rate and portfolio structure depend on an agent's wealth due to constrained participation in the use of financial intermediation service. While we consider the effect of a participation constraint as an extension in Section 7, no such constraint exists in the baseline considered here. But everybody has to expend a certain sum to survive. This biases saving rate and portfolio structure. If people get richer the pressure of the subsistence requirements diminishes. There are of course other important differences to Greenwood and Jovanovic. In particular, all forms of saving require costly financial intermediation in our framework. Moreover, our focus is on inequality in labor income rather than wealth inequality and on structural change rather than growth. 
for $p=1$ the square-bracketed term reduces to one.)

Proof. Part a) follows immediately from (20) and (21). For b) the definition of $\bar{y}$ in (18) is used.

\subsection{Aggregate demand for goods and financial services}

Saving and expenditure behavior follow affine-linear functions. Therefore, aggregate behavior depends on two things: The level of aggregate income and the number of people over which the income is distributed. The latter comes in through the fact that subsistence requirements are bound to the existence of an agent, independent of her or his income.

Aggregating the two pools of agents, we have

$$
N=\bar{L}+\bar{H}
$$

for the size of the population and

$$
W=w_{L} b_{L} \bar{L}+w_{H} b_{H} \bar{H}
$$

for the level of aggregate income. In view of (11), the latter amounts to

$$
W=A_{x} \Gamma_{x} b_{L} \bar{L} \omega^{-\alpha_{x}}(1+\omega k)
$$

The following fact shows that aggregate income, measured in units of $X$, is an increasing function of the skill premium $\left(\omega=w_{H} / w_{L}\right)$.

Fact 5. Under Assumption 1, $W$ is increasing in $\omega$. We have

$$
\frac{\partial W}{\partial \omega}=A_{w} \omega^{-\alpha_{x}}\left(1-\alpha_{x}\right)\left(k-\kappa_{x}\right)>0
$$


with $A_{w} \equiv A_{x} \Gamma_{x} b_{L} \bar{L}$

Proof. According to (26),

$$
\begin{aligned}
\frac{\partial W}{\partial \omega} & =A_{w} \omega^{-\alpha_{x}}\left[-\frac{\alpha_{x}}{\omega}(1+\omega k)+k\right] \\
& =A_{w} \omega^{-\alpha_{x}}\left[-\frac{\alpha_{x}}{\omega}+\left(1-\alpha_{x}\right) k\right]=A_{w} \omega^{-\alpha_{x}}\left(1-\alpha_{x}\right)\left[k-\frac{\alpha_{x}}{1-\alpha_{x}} \frac{w_{L}}{w_{H}}\right] .
\end{aligned}
$$

According to (9),

$$
\frac{\alpha_{x}}{1-\alpha_{x}}=\frac{w_{H} a_{x}^{H}}{w_{L} a_{x}^{L}}
$$

Thus, the square-bracketed term reduces to $k-\kappa_{x}$, which is positive if Assumption 1 holds.

Financial services provision is more skill intensive than goods production, at least on average. Therefore, in terms of goods, aggregate wage income rises with the skill premium. A different matter is the impact of the skill premium on the purchasing power for financial services, the price of which rises too with the skill premium.

Aggregating individual investments in deposits, given by (20), we obtain

$$
D=\left(s_{d} \frac{\delta}{1+\delta} \frac{\bar{w}-\bar{y}}{1+p_{z_{1}}}+\frac{\overline{e_{1}}}{r}\right) N
$$

where $\bar{w} \equiv \frac{W}{N}$ denotes average income. In an analogous way, we have from (21):

$$
F=s_{f} \frac{\delta}{1+\delta} \frac{\bar{w}-\bar{y}}{1+p_{z_{2}}} N, \quad F_{\theta}=\pi_{\theta} F
$$

for aggregate investments in securities. Aggregate savings are

$$
S=\left[\frac{\delta}{1+\delta} \frac{\bar{w}-\bar{y}}{1+p_{z_{1}}}\left(s_{d}+\frac{s_{f}}{p}\right)+\frac{\overline{e_{1}}}{r}\right] N
$$

and aggregate current expenditures are

$$
E_{0}=\left[\frac{1}{1+\delta}(\bar{w}-\bar{y})+\overline{e_{0}}\right] N
$$




\section{The effect of the skill premium on the sec- toral structure}

In a general equilibrium, sectoral structure and skill premium are determined simultaneously. As an intermediate step we characterize the sectoral structure as a function of the skill premium and exogenous parameters, keeping in mind that in the end the skill premium depends on exogenous parameters too. Not all possible values of skill premia and parameters are of interest, but only those which are reasonable candidates for a general equilibrium, in which both financial sectors are viable, the subsistence of all agents is feasible and a positive skill premium results. The following paragraphs characterize the set of parameter configurations which guarantee these equilibrium properties.

Assumption 1 that financial service provision is more skill intensive than goods production $\left(\kappa_{x}<k<\kappa_{z}\right)$ is equivalent to $\frac{\gamma_{x}}{k}<\omega<\frac{\gamma_{z}}{k}$ as we know from (9). At $\omega_{\min } \equiv \frac{\gamma_{x}}{k}$ the $Z$-sector vanishes and beyond $\omega_{\max } \equiv \frac{\gamma_{z}}{k}$ there would be no longer an $X$-sector. Hence, we consider the range $\omega \in\left(\omega_{\min }, \omega_{\max }\right)$ in our search for the equilibrium skill premium.

Moreover, according to Fact $3, \omega<\omega_{L}^{+}\left(A_{x}, A_{z}, b_{L}, \overline{e_{0}}, \frac{\bar{e}}{r}\right)$ is required for guaranteeing subsistence for low-skilled agents. $\omega_{L}^{+} \geq \omega_{\max }$ holds if $A_{x}, A_{z}$ and $b_{L}$ are large enough (for given $\overline{e_{0}}, \frac{\overline{e_{1}}}{r}$ ), or $\overline{e_{0}}$ and $\frac{\overline{e_{1}}}{r}$ are not too high (for given $\left.A_{x}, A_{z}, b_{L}\right)$. If $\omega_{L}^{+}<\omega_{\max }$, only range $\omega \in\left(\omega_{\min }, \omega_{L}^{+}\right)$is feasible.

Finally, $\omega \geq b_{L} / b_{H}$ is required for $y^{H} \geq y^{L}$. This is guaranteed if $\omega_{\min } \geq$ $b_{L} / b_{H}$, which is equivalent to

$$
\gamma_{x} \geq \frac{\bar{H}}{\bar{L}}
$$


In terms of exogenous fundamentals, the requirements mean that we restrict the possible combinations of exogenous model parameters

$$
\xi=\left\{A_{x}, A_{z_{1}}, A_{z_{2}}, \alpha_{x}, \alpha_{z_{1}}, \alpha_{z_{2}}, b_{L}, b_{H}, \bar{H}, \bar{L}, \overline{e_{0}}, \frac{\overline{e_{1}}}{r}, \rho, \mu, \delta\right\}
$$

to the following set:

$$
\Xi_{0} \equiv\left\{\xi \mid \frac{\bar{H}}{\bar{L}} \leq \gamma_{x}, \frac{\gamma_{x}}{k}<\tilde{\omega}_{\max }\right\}
$$

where $k=\frac{b_{H} \bar{H}}{b_{L} \bar{L}}$ and $\tilde{\omega}_{\max } \equiv \min \left\{\omega_{\max }, \omega_{L}^{+}\left(A_{x}, A_{z_{1}}, b_{L}, \overline{e_{0}}, \frac{\overline{e_{1}}}{r}\right)\right\}$.

In general, the interaction of the allocation of resources between the $X$-sector and the $Z$-sector, on the one hand, and the allocation within the Z-sector on $Z_{1}$ and $Z_{2}$, on the other hand, are hard to disentangle in an economically transparent way. For qualitatively robust insights into important channels we have to reduce complexity on either the demand or the supply side. In the benchmark analysis presented in Section 5.1, 5.2 and 6, we shut down relative price effects within the financial sector by assuming identical technologies for $Z_{1}$ and $Z_{2}$.

Assumption 2. $\alpha_{z_{1}}=\alpha_{z_{2}}=\alpha_{z}>\alpha_{x}$ and $A_{z_{1}}=A_{z_{2}}=A_{z} 11$

Assumption 2 allows us to put focus on the income effects. In Section 8 we consider the case $\alpha_{z_{2}}>\alpha_{z_{1}}=\alpha_{x}$ as a robustness check. Moreover, in the quantitative implementation of the model we solve the model numerically for $\alpha_{j}$ values that match U.S. data where $\alpha_{z_{2}}>\alpha_{z_{1}}>\alpha_{x}$.

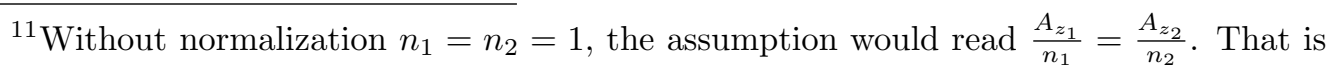
the provision of financial services per unit of saving must be equal in the two sub-sectors. For instance, new financial services may be provided more productively than traditional services, but, at the same time, more units of services are needed to transform a unit of saving into future payoff by complex rather than simple financial products.
} 
We analyze first the impact of an increase in the skill premium on structural change within the financial sector.

\subsection{Within change}

The value added in sub-sector $Z_{i}, i=\{1,2\}$, is equal to aggregate expenditure on the produced services. According to (28) and (29), aggregate expenditures for financial services have the following structure:

$$
\frac{p_{z_{2}} F}{p_{z_{1}} D}=\frac{s_{f} \zeta \bar{\eta}}{s_{d} \bar{\eta}+\frac{1+\delta}{\delta} \frac{\bar{e}_{1}}{r}} \equiv \Phi\left(\underset{+}{s_{d}, s_{f}}, \frac{\overline{e_{1}}}{\underline{-}_{+}}, \underset{+}{\zeta}(\omega), \bar{\eta}(\omega)\right)
$$

where $\zeta(\omega) \equiv \frac{p_{z_{2}}}{p_{z_{1}}} \frac{1+p_{z_{1}}}{1+p_{z_{2}}}, \bar{\eta}(\omega) \equiv \frac{\bar{w}-\bar{y}}{1+p_{z_{1}}}$ and $s_{d}, s_{f}$ are defined in (22). While the impacts of saving propensities $s_{d}$ and $s_{f}$ on the within structure are straightforward, the role of the skill premium is in general ambiguous. $\zeta(\omega)$ expresses relative price effects. Since $p_{z_{1}}=p_{z_{2}}=p_{z}$ under Assumption 2, $\zeta(\omega)$ reduces to one (see discussion in Section 8 for the case of changing relative prices within the Z-sector). $\bar{\eta}(\omega)$ is the average supernumerary income weighted by the cost of future subsistence. It captures the income effect on within structural change. If $\overline{e_{1}}=0$, there is no income effect on the demand structure for financial services. For $\overline{e_{1}}>0$, the impact of the skill premium on the value-added share $\Phi$ of sector $Z_{2}$ compared to $Z_{1}$ depends in the benchmark only on the shape of $\bar{\eta}(\omega)$. The following lemma characterizes the properties of $\bar{\eta}(\omega)$.

Lemma 1. Let exogenous model parameters belong to $\Xi_{0}$ defined in (32).

a) If $\xi \in \Xi_{1} \equiv \Xi_{0} \cap\left\{\xi \mid \alpha_{x}+\alpha_{z}>1\right\}$, then there exists a threshold 
$\underline{\omega}\left(A_{?}, A_{?}, \underset{-}{A_{z}}, \underset{?}{\frac{b_{L} \bar{L}}{N}}, \overline{e_{0}}\right)$ with $\left.\frac{\partial \bar{\eta}}{\partial \omega}\right|_{\omega=\underline{\omega}}=0$ so that:

$$
\begin{aligned}
& \frac{\partial \bar{\eta}}{\partial \omega}<0 \text { for } \omega<\underline{\omega}, \\
& \frac{\partial \bar{\eta}}{\partial \omega}>0 \text { for } \omega>\underline{\omega} .
\end{aligned}
$$

Especially, define $\Xi_{D}^{1} \equiv\left\{\xi \mid \underline{\omega}>\omega_{\min }\right\}$ and $\Xi_{D}^{2} \equiv\left\{\xi \mid \underline{\omega}<\tilde{\omega}_{\max }\right\}$. If $\xi \in$ $\Xi_{1}-\Xi_{D}^{1}$, then $\frac{\partial \bar{\eta}}{\partial \omega}>0$ for all $\omega \in\left(\omega_{\min }, \tilde{\omega}_{\max }\right)$. If $\xi \in \Xi_{1}-\Xi_{D}^{2}$, then $\frac{\partial \bar{\eta}}{\partial \omega}<0$ for all $\omega \in\left(\omega_{\min }, \tilde{\omega}_{\max }\right)$.

b) For the comparative static analysis we have:

$$
\bar{\eta}\left(\omega \mid \begin{array}{c}
A_{x}, A_{z}, \underset{+}{k}, \frac{b_{L} \bar{L}}{N}, \underset{+}{\overline{e_{0}}}, \frac{\overline{e_{1}}}{r} \\
+
\end{array}\right)
$$

Proof. Appendix C.

On the one hand, a higher $\omega$ raises the average wage. On the other hand, the prices of financial services are increasing, which has a negative effect on the purchasing power. According to Lemma 1, the first effect dominates if the skill premium is sufficiently high.

In sum, we have the following partial results about within structural change in the finance sector.

Proposition 2. Let $\overline{e_{1}}>0$.

a) A rise in the skill premium leads to structural change from sub-sector $Z_{1}$ to sub-sector $Z_{2}$ (in terms of value-added) at high levels of the skill premium $(\omega>\underline{\omega})$ and to structural change from $Z_{2}$ to $Z_{1}$ at low levels of skill premium. 
b) For a given skill premium, a rise of $A_{x}, A_{z}, k, \frac{b_{L} \bar{L}}{N}$ or a decline of $\overline{e_{0}}, \frac{\overline{e_{1}}}{r}$ lead to structural change from $Z_{1}$ to $Z_{2}$. A rise of $\mu$ or a decline of $\rho$ also lead to change from $Z_{1}$ to $Z_{2}$, even if $\overline{e_{1}}=0$.

Proof. (33), Lemma 1 and the fact that a rise in $\mu$ or a decline in $\rho$ raise $s_{f}$ (at cost of $s_{d}$ ).

The proposition describes only a partial effect. For a full comparative-static equilibrium analysis, we have to combine the direct effects of exogenous fundamentals with their indirect effects through the equilibrium skill premium. We come back on the total effects in Section 6.4.

\subsection{Between change}

For $\alpha_{z_{1}}=\alpha_{z_{2}}=\alpha_{z}$ and $A_{z_{1}}=A_{z_{2}}=A_{z}$, aggregate supply of financial services reduces to:

$$
Z\left(=Z_{1}+Z_{2}\right)=A_{z} L_{z} \kappa_{z}^{\alpha}
$$

The allocation between the $X$-and the $Z$-sector is then determined by the resource constraints:

$$
\begin{aligned}
& a_{x}^{L} X+a_{z}^{L} Z=b_{L} \bar{L}, \\
& a_{x}^{H} X+a_{z}^{H} Z=b_{H} \bar{H} .
\end{aligned}
$$

In an analogous way to (14), we get from this as solution:

$$
X=\frac{b_{L} \bar{L}}{a_{x}^{L}} \frac{\kappa_{z}-k}{\kappa_{z}-\kappa_{x}}, \quad Z=\frac{b_{L} \bar{L}}{a_{z}^{L}} \frac{k-\kappa_{x}}{\kappa_{z}-\kappa_{x}} .
$$


Substituting $a_{j}^{L}=\frac{1}{A_{j} \kappa_{j}^{\alpha_{j}}}$, we have:

$$
\frac{Z}{X}=\frac{A_{z}}{A_{x}} \psi(\underset{+}{\omega}, k), \quad \psi(\omega, k) \equiv \frac{\kappa_{z}^{\alpha_{z}}}{\kappa_{x}^{\alpha_{x}}} \frac{k-\kappa_{x}}{\kappa_{z}-k} .
$$

This gives us the following result for the comparative-static effects on the supply structure. 12

Proposition 3. An increase in the skill premium shifts the supply structure from goods production to financial services provision. An increase in the high skilled labor share $(k)$ or biased technical change in favor of financial services (so that total factor productivity $A_{z}$ rises relative to $A_{x}$ ) have the same effect.

Proof. The signs of the respective partial derivatives in (35) follow from $\kappa_{z}>\kappa_{x}$ and the Rybczynski analysis.

The proposition characterizes the supply structure as a function of exogenous fundamentals and the skill premium. The supply structure interacts with demand, which depends on aggregate income and prices and thus also reacts to the skill premium. To close the analysis, we have to determine the equilibrium skill premium. Section 6.3 will then summarize the general equilibrium effect of the skill premium on the between sectoral structure.

\footnotetext{
12 Note that (35) characterizes the supply structure of labor produced output. If capital is used as set-up capital as in the extended model in Section 7.5 , then $X$ is indeed the total size of final output in the goods sector. In the baseline model considered here there is in addition the output generated for old age consumption by past capital investments. Thus, the total size of goods transactions becomes $\bar{X} \equiv X+r D+\mu R F$ with $X=$ $E_{0}+S=E_{0}+D+F$ and the between structural change ratio is $\bar{\Psi} \equiv \frac{p_{z} D+p_{z} F}{\bar{X}}=$ $\frac{p_{z} D+p_{z} F}{X+r D+\mu R F}$ with $D, F, E_{0}$ and $S$ from (28)-(31). It is, ceteris paribus, increasing in $\omega$ if $S^{\prime} E_{0}-S E_{0}^{\prime}-(\mu R-r)\left(D F^{\prime}-F D^{\prime}\right)>0$ where $D^{\prime}, F^{\prime}, S^{\prime}$ and $E_{0}^{\prime}$ are the respective derivatives with respect to $\omega$. This means, if the between change $\left(S^{\prime} E_{0}-S E_{0}^{\prime}\right)$ is larger than within change $\left(D F^{\prime}-F D^{\prime}\right)$ multiplied with the return difference $(\mu R-r)$.
} 


\section{General equilibrium}

Aggregate demand in the $X$-sector is composed of consumer goods demand, $E_{0}$, and investment goods demand, $S=D+F$. On top of it, old agents consume the output generated by the capital they invested in the period before.

Aggregating the individual budget constraints (2), we obtain:

$$
E_{0}+D+F+p_{z_{1}} D+p_{z_{2}} F=W
$$

where $W=W_{x}+W_{z}, W_{x}=X$ and $W_{z}=p_{z_{1}} G^{z_{1}}\left(H_{z_{1}}, L_{z_{1}}\right)+p_{z_{2}} G^{z_{2}}\left(H_{z_{2}}, L_{z_{2}}\right)$. If the $Z_{1}$ and $Z_{2}$-markets are cleared, we have $G^{z_{1}}\left(H_{z_{1}}, L_{z_{1}}\right)=D$ and $G^{z_{2}}\left(H_{z_{2}}, L_{z_{2}}\right)=F$ so that (36) reduces to

$$
E_{0}+D+F=X
$$

Thus, the goods market is automatically cleared if the markets for financial services are cleared.

Aggregate demand for financial services comes from savings in deposits $D$ and savings in securities F. Adding up (28) and (29), we have for aggregate demand in the $Z$-sector

$$
Z^{D}=\left(\frac{\delta}{1+\delta} \frac{\bar{w}-\bar{y}}{1+p_{z}}+\frac{\overline{e_{1}}}{r}\right) N
$$

From (34) we know that aggregate $Z$-supply in a production equilibrium is

$$
Z^{S}=A_{z} b_{L} \bar{L} \kappa_{z}^{\alpha_{z}} \frac{k-\kappa_{x}}{\kappa_{z}-\kappa_{x}}
$$

where $a_{z}^{L}=\frac{1}{A_{z} \kappa_{z}^{\alpha z}}$ was used. 


\subsection{Existence, uniqueness and stability of equilibrium}

Both market sides are functions of $\omega$ (which works through $\bar{w}$ and $p_{z}$ on the demand side and through skill intensities $\kappa_{x}, \kappa_{z}$ on the supply side). For a stable equilibrium, the condition

$$
\frac{d Z^{D}}{d \omega}<\frac{d Z^{S}}{d \omega}
$$

is required at the market clearing $\omega$-value. (Since $p_{z}$ is increasing in $\omega$, inequality (39) guarantees that a rise in price $p_{z}$ goes hand in hand with a reduction of excess demand and a fall in the price reduces excess supply.)

The supply function is characterized by the following fact.

Fact 6. $Z^{S}$ is an increasing strictly concave function of $\omega$ starting at $\lim _{\omega \rightarrow \omega_{\min }} Z^{S}=0$ and approaching $A_{z} b_{L} \bar{L} k^{\alpha_{z}}$ at $\omega_{\max }$. More specifically,

$$
Z^{S}=A_{z} b_{L} \bar{L} \frac{\gamma_{z}^{\alpha_{z}}}{\gamma_{z}-\gamma_{x}} g(\underset{+}{\omega}, k), \quad g(\omega, k)=\omega^{-\alpha_{z}}\left(k \omega-\gamma_{x}\right)
$$

Proof. Appendix C.

For the demand side the following fact applies.

Fact 7. Aggregate demand for financial services is given by:

$$
Z^{D}=\left[\frac{\delta}{1+\delta} \bar{\eta}\left(\omega \mid \begin{array}{c}
A_{x}, \underset{+}{A_{z}}, \underset{+}{k}, \underset{+}{\frac{b_{L} \bar{L}}{N}}, \underset{-}{\overline{e_{0}}}, \frac{\overline{e_{1}}}{r} \\
-\underset{+}{r}
\end{array}\right)+\frac{\overline{e_{1}}}{r}\right] N
$$

where $\bar{\eta}$ was discussed in Lemma 1, For all $\xi \in \Xi_{1}, Z^{D}$ is defined and positive on the $\omega$-domain $\left(\omega_{\min }, \tilde{\omega}_{\max }\right)$. Moreover, it is either $U$-shaped in $\omega$ (for $\xi \in \Xi_{D} \equiv \Xi_{1} \cap \Xi_{D}^{1} \cap \Xi_{D}^{2}$ ), increasing over the entire domain (for $\xi \in \Xi_{1}-\Xi_{D}^{1}$ ) or declining for all $\omega$ (if $\xi \in \Xi_{1}-\Xi_{D}^{2}$ ). 
Proof. Equation (37) and Lemma 1.

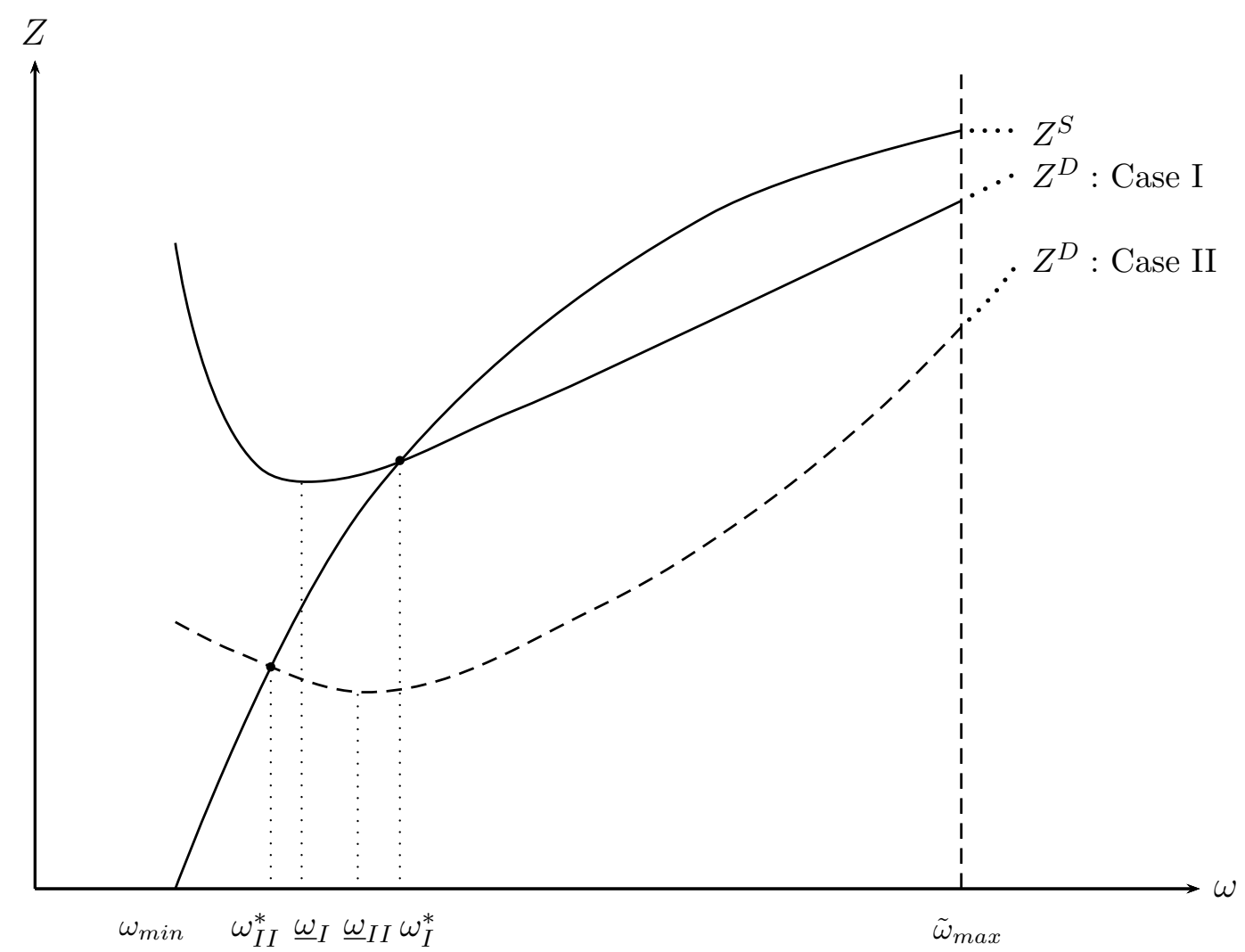

Figure 1: Equilibrium in the financial service sector.

Figure 1 shows in the $(\omega, Z)$-space the supply and demand curves under the assumption that

$$
Z^{D}\left(\tilde{\omega}_{\max }\right)<Z^{S}\left(\tilde{\omega}_{\max }\right)
$$

where $\tilde{\omega}_{\max }$ was defined in (32) 13

\footnotetext{
${ }^{13}$ If $\tilde{\omega}_{\max }=\omega_{L}^{+}$, then $Z^{D}(\tilde{\omega})$ is to be read as $Z^{D}(\omega)<Z^{S}(\omega)$ for all $\omega<\omega_{L}^{+}-\epsilon$, with $\epsilon$ arbitrarily small. Figure 1 assumes $\xi \in \Xi_{D}$; yet, from Fact 7 it is obvious that for $\xi \in \Xi_{1}-\Xi_{D}^{1}$ the $Z^{D}$-curve would cross the $Z^{S}$-curve at $\omega^{*}$ as in Case I, whereas for $\xi \in \Xi_{1}-\Xi_{D}^{2}$ we would have at $\omega^{*}$ the situation illustrated in Case II.
} 
If inequality (41) holds, then the market clearing condition $Z^{D}(\omega)=Z^{S}(\omega)$ has a unique solution $\omega^{*}$ within $\left(\omega_{\min }, \tilde{\omega}_{\max }\right)$. Moreover, stability condition (39) is fulfilled at $\omega^{*}$. This establishes the following proposition.

Proposition 4. Define $\Xi_{E}=\Xi_{1} \cap\left\{\xi \mid Z^{D}\left(\tilde{\omega}_{\max }\right)<Z^{S}\left(\tilde{\omega}_{\max }\right)\right\}$. For all $\xi \in$ $\Xi_{E}$, there exists a unique and stable equilibrium.

Proof. Continuity of $Z^{D}$ on $\omega \in\left(\omega_{\min }, \tilde{\omega}_{\max }\right)$ and properties of the shape of $Z^{D}$ established in Fact 7 .

\subsection{Equilibrium skill premium}

For the comparative-static equilibrium analysis, we have to look at the excess demand function $Z^{D}-Z^{S}$. Because of stability condition $\frac{\partial\left(Z^{D}-Z^{S}\right)}{\partial \omega}<0$, we know that for any exogenous change of a component $\mathfrak{i}$ of $\xi \in \Xi_{E}$

$$
\operatorname{sign} \frac{\partial \omega^{*}}{\partial \mathfrak{i}}=\left.\operatorname{sign} \frac{\partial\left(Z^{D}-Z^{S}\right)}{\partial \mathfrak{i}}\right|_{Z^{D}=Z^{S}}
$$

For signing the impact of exogenous fundamentals on the equilibrium, we express excessive demand explicitly as a function of model parameters. Using (26) and (12), we have

$$
\frac{\bar{w} N}{1+p_{z}}=A_{x} b_{L} \bar{L} D_{1}\left(\omega \mid \frac{A_{z}}{A_{x}}, \underset{+}{+}\right),
$$

where $D_{1} \equiv \frac{\Gamma_{x}(1+\omega k)}{\omega^{\alpha x}+\frac{A_{x} \Gamma_{x}}{A_{z} \Gamma_{z} \omega_{z}}}$ and the signs below parameters in (42) express the signs of their impact on $D_{1}$. Term $D_{1}$ captures the purchasing power effect.

Moreover, substituting (12) for $p_{z_{1}}$ in (18) we can write the term $\frac{\delta}{1+\delta} \frac{\bar{y}}{1+p_{z}}-\frac{\overline{e_{1}}}{r}$ 
in the form:

$$
D_{0}\left(\omega \mid \frac{A_{z}}{A_{x}}, \overline{e_{0}}, \frac{\overline{e_{1}}}{r}\right)=\frac{1}{1+\delta}\left[\frac{\delta \overline{e_{0}}}{1+\frac{A_{x} \Gamma_{x}}{A_{z} \Gamma_{z}} \omega^{\alpha_{z}-\alpha_{x}}}-\frac{\overline{e_{1}}}{r}\right] .
$$

Term $D_{0}$ captures the effect of the subsistence requirements on the aggregate demand for financial services. The sign of the square-bracketed term is positive if the present subsistence expenditure $\overline{e_{0}}$ dominates the future subsistence expenditure $\overline{e_{1}}$. It is negative if $\overline{e_{1}}$ dominates $\overline{e_{0}}$. For the economic interpretation of the relevant notion of dominance it is useful to recall $\frac{A_{x} \Gamma_{x}}{A_{z} \Gamma_{z}} \omega^{\alpha_{z}-\alpha_{x}}=p_{z}$. Thus $D_{0}\left(\omega \mid \frac{A_{z}}{A_{x}}, \overline{e_{0}}, \frac{\overline{e_{1}}}{r}\right)>0(=,<0)$ if and only if

$$
\frac{\delta \overline{e_{0}}}{1+p_{z}}>\frac{\overline{e_{1}}}{r}\left(=,<\frac{\overline{e_{1}}}{r}, \text { resp. }\right) \text {. }
$$

This is exactly the condition for a rising (constant, declining, resp.) saving rate derived in Fact 4,b). (Note that $p=1$ in the benchmark case.) If present subsistence expenditures are more pressing than future ones, people save more and demand more financial services if they become richer and get farther away from subsistence problems.

Using $D_{0}$ and (42) in (37) and combining the result with (40), we conclude that $Z^{D}-Z^{S}$ is equal to the term

$$
A_{x} b_{L} \bar{L}\left[\frac{\delta}{1+\delta} D_{1}\left(\omega \mid \frac{A_{z}}{A_{x}}, k\right)-\frac{N}{+}+\frac{A_{x} b_{L} \bar{L}}{+} D_{0}\left(\omega \mid \frac{A_{z}}{A_{x}}, \overline{+}+\underset{+}{+}, \frac{\overline{e_{1}}}{r}\right)-\frac{A_{z}}{A_{x}} \frac{\gamma_{z}^{\alpha_{z}}}{\gamma_{z}-\gamma_{x}} g(\omega, k)\right] .
$$

Hence, $\overline{e_{1}}$ has a positive impact on $Z^{D}-Z^{S}$ and thus on $\omega^{*} ; \overline{e_{0}}$ has a negative impact. $\frac{A_{z}}{A_{x}}$ and $k$ have opposing effects so that their impacts cannot be signed unambiguously by inspection of (45). 
The most interesting question is how technical change affects the equilibrium skill premium. For this we have to look at the impact of $\frac{A_{x} b_{L} \bar{L}}{N}$ on $Z^{D}-Z^{S}$. (Since $\frac{A_{z}}{A_{x}}$ has an ambiguous effect, we only consider uniform progress across sectors, that is, total factor productivity $A_{z}$ rises pari passu with $A_{x}$.) The answer depends on condition (44)). If $\frac{\delta \overline{e_{0}}}{1+p_{z}}>\frac{\overline{e_{1}}}{r}, D_{0}$ is positive and $\omega^{*}$ increases if $\frac{A_{x} b_{L} \bar{L}}{N}$ rises. If $\frac{\delta \overline{e_{0}}}{1+p_{z}}<\frac{\overline{e_{1}}}{r}$, then $D_{0}$ is negative and $\omega^{*}$ declines if $\frac{A_{x} b_{L} \bar{L}}{N}$ increases. For $\bar{e}_{0}=\bar{e}_{1}=0, \frac{A_{x} b_{L} \bar{L}}{N}$ has no effect.

In sum, we have the following partial effects of the parameters on the equilibrium skill premium:14

$$
\omega^{*}\left(\underset{A_{x}}{\frac{A_{z}}{A_{x}}}, \underset{?}{k}, \frac{A_{x} b_{L} \bar{L}}{N}, \underset{+/-}{\overline{e_{0}}}, \frac{\overline{e_{1}}}{r}\right),
$$

where the impact of $\frac{A_{x} b_{L} \bar{L}}{N}$ depends on the cases discussed above.

All addressed effects refer to the partial derivatives, that is, they hold under the condition that other parameters do not change simultaneously. Economically this means, the effects come from a single source. In particular, for the effect of $\frac{b_{L} \bar{L}}{N}$ on $\omega^{*}$, skill richness $k=\frac{b_{H} \bar{H}}{b_{L} \bar{L}}$ is held constant in the comparison. This requires a careful interpretation of the described effect of $\frac{b_{L} \bar{L}}{N}$. The following fact provides an economically meaningful description of the variations which are consistent with a constant $k$ and a rise in $\frac{b_{L} \bar{L}}{N}$.

Fact 8. A rise in $\frac{b_{L} \bar{L}}{N}$ is consistent with a constant $k$ if there is:

a) Uniform factor-augmenting technical progress, raising $b_{L}$ pari passu with $b_{H}$.

\footnotetext{
${ }^{14}$ The signs below the parameters represent the partial derivatives. The combination $+/-$ is used for pointing to case-dependent impacts. A question mark means that the impact of the respective parameter cannot be signed without further investigation.
} 
b) A shift in labor supply from unskilled to skilled labor accompanied by factor augmenting progress that is biased towards the low-skilled. (Note that such low-skilled labor augmentation depresses the relative wage of the unskilled - like skill-biased technical change.)

Proof. Use $N=\bar{L}+\bar{H}$ for $\frac{N}{b_{L} \bar{L}}=\frac{1+\frac{\bar{H}}{\bar{L}}}{b_{L}}$. Hence, $k=\frac{b_{H} \bar{H}}{b_{L} \bar{L}}$ remains constant under a decrease in $\frac{N}{b_{L} \bar{L}}$ if either $b_{L}$ and $b_{H}$ rise proportionally and $\bar{H} / \bar{L}$ does not change or $\frac{\bar{H}}{\bar{L}}$ rises and $b_{L}$ rises such that $\frac{b_{L}}{b_{H}}$ grows proportionally to $\overline{\bar{H}}$.

With these clarification the following proposition summarizes the comparative static equilibrium results.

Proposition 5. Let $\bar{e}_{0}>$ or $\bar{e}_{1}>0$.

a) Uniform productivity growth across sectors (raising $A_{x}$ and $A_{z}$ proportionally) or uniform factor-augmenting technical progress (raising $b_{L}$ and $b_{H}$ proportionally) have a positive effect on the equilibrium skill premium if the present subsistence expenditure dominates the future subsistence expenditure; if the future subsistence expenditure dominates, then the skill premium declines.

b) A shift of labor supply from unskilled to skilled work accompanied by factor augmentation which is biased towards low-skilled labor has the same effect on the equilibrium skill premium as factor augmenting progress that is uniform.

c) The equilibrium skill premium rises, if future subsistence expenditure $\left(\overline{e_{1}}\right)$ increases or present subsistence expenditure $\left(\overline{e_{0}}\right)$ declines. 
Proof. Fact 8 and main text.

For the economic intuition behind a) and b) it is useful to remember Fact 4.b). If present subsistence expenditure weighs more than future subsistence requirements then the saving rate and therefore demand for financial services are rising with income. Since the financial services are more skill intensive than goods, this rise of demand induces a rise in the skill premium. The rising income in turn comes from technical progress or a better educated workforce. The intuition for c) is: If future subsistence expenditure is high, agents have to save more and need more financial services; and if present subsistence expenditure is low, they can afford to save more and to spend more for financial services.

It is worth noting that positive subsistence expenditure $\left(\bar{e}_{0}>0\right.$ or $\left.\bar{e}_{1}>0\right)$ is essential for the comparative-static results stated in Proposition 5. For $\bar{e}_{0}=\bar{e}_{1}=0$, expression (45) boils down to

$$
A_{x} b_{L} \bar{L}\left[\frac{\delta}{1+\delta} D_{1}\left(\omega \mid \begin{array}{c}
\frac{A_{z}}{A_{x}}, k \\
+
\end{array}\right)-\frac{A_{z}}{A_{x}} \frac{\gamma_{z}^{\alpha_{z}}}{\gamma_{z}-\gamma_{x}} g\left(\begin{array}{c}
\omega, k \\
+
\end{array}\right)\right] .
$$

Thus, uniform productivity growth has no effect in this case nor has $\frac{b_{L} \bar{L}}{N}$.

\subsection{Structural change between production and finan- cial service sectors}

Combining the results of subsections 6.2 and 5.2 , we obtain the following results for the structural change between production and financial services in equilibrium: 
Proposition 6. For all $\xi \in \Xi_{E}$, at given $\frac{A_{z}}{A_{x}}, k$, any change in other exogenous fundamental which raises (lowers) the skill premium leads to structural change from $X$ to $Z$ ( $Z$ to $X$, respectively).

Proof. Equation (35). Since $p_{z}$ rises with $\omega$, the rise of $\psi$ immediately implies that $\frac{p_{z} Z}{X}$ rises too.

\subsection{Structural change within the financial sector}

Finally, for structural change within the financial sector, we have the following results in equilibrium:

Proposition 7. Let $\underline{\omega}$ be the threshold defined in Lemma 1 and parameters fulfill $\xi \in \Xi_{E}$. Then, under the assumption that prices do not differ across financial services, the following comparative static results hold for structural change within the financial sector as long as $\bar{e}_{1}>0$ :

a) At high levels of the skill premium ( $\left.\omega^{*}>\underline{\omega}\right)$, a fall of $\overline{e_{0}}$ leads to a shift from $Z_{1}$ to $Z_{2}$. In addition, if present subsistence expenditure dominates future subsistence expenditure, uniform productivity growth across sectors (i.e. a proportional rise of $A_{x}$ and $A_{z}$ ) as well as an increase in $\frac{b_{L} \bar{L}}{N}$ change the structure within the financial sector from $Z_{1}$ towards $Z_{2}$. According to Proposition 5 and [6, these changes induce an increase in the inequality level $\omega^{*}$, accompanied by a simultaneous structural change from the goods to the financial service sector.

b) At low levels of the skill premium ( $\left.\omega^{*}<\underline{\omega}\right)$, a fall of $\overline{e_{1}}$ leads to a shift from $Z_{1}$ to $Z_{2}$. In addition, if future subsistence expenditure dominates present 
subsistence expenditure, uniform productivity growth across sectors as well as and an increase in $\frac{b_{L} \bar{L}}{N}$ change the structure within the financial sector from $Z_{1}$ towards $Z_{2}$. However, according to Proposition 5 and [6, these changes correspond to a decrease in the inequality level $\omega^{*}$, accompanied by a simultaneous a structural change from the financial service to the goods sector.

c) Financial product innovation (a rise of $\mu$ ) or rising attractiveness of risky investments (a decline of $\rho$ ) lead to structural change from $Z_{1}$ to $Z_{2}$, even if $\bar{e}_{1}=0$.

Proof. Using (33), (46), and Lemma 1, we have

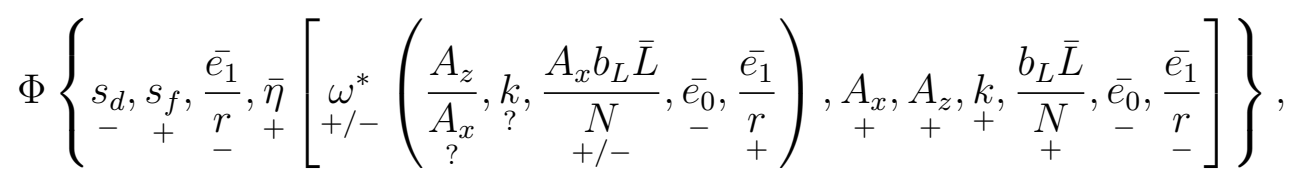

where the signs below the parameters show the sign of the respective partial derivative of the functions $\Phi\{\cdot\}, \bar{\eta}[\cdot]$ and $\omega^{*}(\cdot)$. The plus below $\omega^{*}$ applies for $\omega^{*}>\underline{\omega}$, the minus for $\omega^{*}<\underline{\omega}$. The plus below $\frac{A_{x} b_{L} \bar{L}}{N}$ applies for the case that $\bar{e}_{0}$ dominates $\bar{e}_{1}$; the minus applies if $\bar{e}_{1}$ dominates $\bar{e}_{0}$. For the impacts of $\mu$ and $\rho$ note that $s_{f}$ is rising and $s_{d}$ is declining in $\mu$ and rising in $\rho$.

It is worth noting that for $\overline{e_{1}}=0$ there is no income effect on the portfolio structure so that the channel between skill premium and financial structure is shut down. Since in the benchmark considered here relative price effects within the financial sector were shut down too, for $\overline{e_{1}}=0$ only financial innovation (a rise in $\mu$ ) and rising relative returns on risky investment (a decline of $\rho$ ) remain as sources of structural change within the financial sector. This will change in the model variant with different technologies for $Z_{1}$ and $Z_{2}$ considered in Section 8. 
The punchline of the general equilibrium analysis in the baseline model is: When the skill premium has reached a certain level, a rise in average income leads to rising inequality and to two fold structural change towards and within the financial sector simultaneously. The rise in income can be triggered by a general rise of productivity or by an increased selection of the population into higher education (accompanied by labor augmenting progress that makes low-skilled labor abundant relative to skilled labor). The income effects generated by technical progress or education are robust drivers of the developments outlined at the beginning of this paper. They can explain a rising skill premium and the twofold structural change towards and within finance by a single source, holding everything else constant. Yet, of course, in reality the effects triggered by this source are overlaid by many other things that happen at the same time. The model points to a series of other exogenous fundamentals that affect skill premium and economic structure. Thus, the specific combination of determinants that actually determine the observed patterns of inequality and structural change can only be identified by empirical analysis. The quantitative analysis in Section 9 illustrates possible combinations of exogenous factors which are consistent with the development observed from 1980 onwards. Before turning to the quantitative analysis, we want to add realism to the model by considering extensions which account for important aspects that have been neglected in the analysis presented so far. 


\section{Extensions}

Five extensions are considered: Fixed costs in the financial sector, rents in the financial sector, distorted portfolio choices of households, participation constraints in finance sub-sector $Z_{2}$ and set-up capital for firms. Like the equilibrium analysis in the benchmark, the extended analysis is based on Assumption 2. Moreover, for avoiding too many case distinctions, dominance of $\bar{e}_{0}$ over $\bar{e}_{1}$ is assumed in this section.

\subsection{Fixed costs in the financial sector}

Suppose that financial services are provided by banks. A bank $b$, serving $N_{b}$ clients, needs $K_{b}=f_{B} N_{b}$ units of goods to set up the capacity to serve them. We assume that the fixed cost $K_{b}$ is financed by a lump-sum fee

$$
\tau=f_{B}
$$

imposed on the clients. That is, bank size and number of banks affect neither aggregate fixed costs

$$
K_{B}=f_{B} N
$$

nor the households' budget constraint. In the latter, $y^{l}$ reduces to $y^{l}-\tau$ so that the supernumerary budget becomes $y^{l}-\bar{y}_{+}$, with $\bar{y}_{+}=\bar{y}+\tau=$ $\overline{e_{0}}+f_{B}+\left(1+p_{z_{1}}\right) \overline{e_{1}} / r$.

Hence, fixed cost $f_{B}$ has the same comparative-static effects on household choices as an increase in subsistence expenditure $\overline{e_{0}}$. For the $X$-market this means, on the one hand, the absorption of $X$ by households' consumption 
and investment is reduced by $K_{B}=f_{B} N$. On the other hand, $K_{B}$ is spent by banks to set up the capacity to serve their clients. In sum, we have

$$
E_{0}-f_{B} N+D+F+K_{B}=X
$$

for the goods market clearing, which reduces to the condition in the benchmark model:

$$
E_{0}+D+F=X
$$

since $f_{B} N=K_{B}$. Hence, goods markets are cleared whenever the $Z$-markets are cleared.

In the markets for financial services, demand is reduced by the fact that $\bar{w}-\bar{y}_{+}$rather than $\bar{w}-\bar{y}$ is now the relevant supernumerary income. The supply side remains unaffected. In equilibrium, the implications of fixed costs can be derived by looking in the benchmark model at the effect of a rise of $\overline{e_{0}}$ to $\overline{e_{0}}+f_{B}$.

Proposition 8. A decline in fixed costs $f_{B}$ has the following effects:

a) The skill premium rises.

b) The between sectoral structure shifts from $X$ to $Z$.

c) The within sectoral structure shifts from $Z_{1}$ to $Z_{2}$ at high levels of the skill premium $\left(\omega^{*}>\underline{\omega}\right)$. At low levels of the skill premium $\left(\omega^{*}<\underline{\omega}\right)$ the effect is ambiguous.

Proof. Comparative-static results for $\overline{e_{0}}$ in Proposition 5, 6, and 7 , 


\subsection{Rents in the financial sector}

Suppose that a club of agents in the finance sector has the power to extract rents from financial service provision 15 One may think of rentiers who have unearned property rights or an elite subgroup of employees in the financial sector. We make two crucial assumptions: First, whoever are the rent extracting agents, they spend the rent like other agents. Thus, the redistribution of rents has no income effect on aggregate demand. (Total subsistence requirements and aggregate supernumerary income remain unchanged). Second, nobody can enter the club from outside so that the rent does not affect labor allocation.

In the presented model, two instruments can be used to extract rents. First, a fixed fee $\tilde{\tau}$ as in extension [.1, but:

$$
\tilde{\tau}>f_{B}
$$

Aggregate rents $\left(\tilde{\tau}-f_{B}\right) N$ are lump-sum redistributed. Everybody pays $\tilde{\tau}$ and an elite $N_{0}$ receives the rent. Thus, average supernumerary income becomes

$$
\bar{w}-\bar{y}-\tilde{\tau}+\frac{N_{0}}{N} \frac{\left(\tilde{\tau}-f_{B}\right) N}{N_{0}}=\bar{w}-\bar{y}-f_{B} .
$$

In this case, the rent has no effects on aggregate income, expenditure structure, labor allocation, relative prices or the skill premium. Nevertheless, there is lump-sum redistribution of income from the real to the financial sector and within the financial sector. This redistribution implies for the

\footnotetext{
${ }^{15}$ As pointed out in the introduction, there is robust evidence that indeed a substantial finance premium exists. This paper deals with the consequences of rents, not with possible explanations why they exist.
} 
sectoral income shares:

$$
\frac{p_{z} Z+\left(\tilde{\tau}-f_{B}\right) N}{X}
$$

and

$$
\frac{p_{z} F+\nu\left(\tilde{\tau}-f_{B}\right) N}{p_{z} D+(1-\nu)\left(\tilde{\tau}-f_{B}\right) N}
$$

respectively, where $\nu$ is the share of the elite rent going to new finance. It is obvious that a rising finance rent increases the total finance share in the economy. For a given rent distribution $\nu$, a rise in $\tilde{\tau}$ raises the income share of new finance relative to traditional finance as long as $\nu D>(1-\nu) F$, that is as long as the new finance share is not too large. A rise in $\nu$ trivially leads to a rise in the new finance share.

A second instrument of rent extraction would be to charge a markup on unit cost prices in the financial sector so that households have to pay

$$
\tilde{p}_{z_{i}}=p_{z_{i}}\left(1+o_{i}\right)
$$

for financial services.

Using (12), we have

$$
\tilde{p}_{z_{i}}=\left(1+o_{i}\right) \frac{A_{x}}{A_{z_{i}}} \frac{\Gamma_{x}}{\Gamma_{z_{i}}} \omega^{\alpha_{z_{i}}-\alpha_{x}}
$$

In the benchmark case with $p_{z_{1}}=p_{z_{2}}$ a rent $o_{1}=o_{2}=o$ decreases $D_{1}$ in (42) to $\frac{A_{x} \Gamma_{x}(1+\omega k)}{\omega^{\alpha}+\frac{(1+o) A_{x} \Gamma x}{A_{z} \Gamma_{z}} \omega^{\alpha_{z}}}$ and decreases $D_{0}$ in (43) to $\frac{1}{1+\delta}\left[\frac{\delta \overline{e_{0}}}{1+(1+o) \frac{A_{x} x_{x}}{A_{z} \Gamma_{z}} \omega^{\alpha_{z}-\alpha_{x}}}-\frac{\overline{e_{1}}}{r}\right]$. Hence, $o$ has an ambiguous impact on $Z_{D}-Z_{S}$ and thus on $\omega^{*}$.

Proposition 9. Rents in the financial sector have the following effects:

a) If rents are extracted by lump sum fees, they have no allocative equilibrium effects. Yet, there is a redistributive effect that raises the finance share 
in total income. The structure of the sub-sector shares within finance depends on how the earned rents are distributed on traditional and new finance, respectively.

b) If rents are extracted by a markup on financial service prices, there is a redistributive effect towards (and within) the financial sector. Yet, the mark ups affect all equilibrium values in a generally ambiguous way.

Proof. Main text.

\subsection{Distorted portfolio choice}

Several empirical studies have pointed out that people get confused in dealing with complex financial markets (see Célérier and Vallée (2014) and the literature discussed there). In our model, the complex part that households have to solve is the choice of the portfolio of the securities. The choice may be based on a wrong assessment of relative risks and returns of different securities. In this case, we have distortion within $Z_{2}$ and consumption levels planned for the future may be deceived by actual payoffs 16 As our study focuses on structural change between $X$ and $Z$ as well as between $Z_{1}$ and $Z_{2}$, we do not consider such distortions here. Rather we focus on distortions coming from misperception of the opportunities to save by securities investment rather than in deposits.

In particular, people may have wrong beliefs $\tilde{\mu}$ about the measure of future environments covered by state-contingent securities, relative to the non-

\footnotetext{
${ }^{16}$ Falkinger (2014) focuses on such distortions in a one sector economy.
} 
covered part of possible future events. They may also misjudge the relative payoff of deposits compared to the payoffs of securities and base their decisions on a distorted $\tilde{\rho}$. Such distortions affect the propensities to save in deposits and in securities. For instance, if agents are euphoric about investments in securities and believe that $\tilde{\mu}>\mu$ or $\tilde{\rho}<\rho$, then $s_{f}$ rises while $s_{d}$ declines. The total propensity to save, however, does not change in the benchmark model with $p_{z_{1}}=p_{z_{2}} .17$ Therefore, the only consequence of $\tilde{\mu}>\mu$ or $\tilde{\rho}<\rho$ is sectoral change within the financial sector. According to (33), $\Phi$ rises.

Proposition 10. Euphoric beliefs about measure or performance of statecontingent financial instruments lead to within sectoral change from $Z_{1}$ to $Z_{2}$. Equilibrium skill premium and $(X, Z)$-structure are not affected in the benchmark model (with identical technologies in $Z_{1}$ and $Z_{2}$ ).

Proof. Equation (33).

\subsection{Participation constraints}

Suppose that a fixed fee $\tau$ is charged only to agents who invest in securities. Moreover, assume that there is a participation constraint:

$$
\begin{gathered}
y^{L}>\bar{y}>y^{L}-\tau, \\
y^{H}>y^{H}-\tau>\bar{y} .
\end{gathered}
$$

\footnotetext{
${ }^{17}$ For $p_{z_{1}} \neq p_{z_{2}}$, however, we would have $s_{d}+\frac{s_{f}}{p}$ for the marginal propensity to save, as shown by (23). Thus, $\mu$ and $\rho$ impact also on $Z^{D}$ and therefore on $\omega$ and all other equilibrium outcomes. See Section 8 for a more detailed discussion.
} 
Then low-skilled agents do not participate in the securities market, while high-skilled agents do. According to equation (B.4) in Appendix B, we have for $l=L$ :

$$
s^{L}=d^{L}=\frac{\delta}{1+\delta} \frac{y^{L}-\bar{y}}{1+p_{z}}+\frac{\bar{e}_{1}}{r} .
$$

For $l=H$, saving behavior is given by (20) and (21) with $\bar{y}_{+}=\bar{y}+\tau$.

This gives us the following aggregate saving levels:

$$
\begin{aligned}
D & =\frac{\delta}{1+\delta} \frac{1}{1+p_{z}}\left[\left(y^{L}-\bar{y}\right) \bar{L}+s_{d}\left(y^{H}-\bar{y}_{+}\right) \bar{H}\right]+\frac{\overline{e_{1}}}{r} N \\
F & =s_{f} \frac{\delta}{1+\delta} \frac{\bar{H}}{1+p_{z}}\left(y^{H}-\bar{y}_{+}\right) \\
S & =\left(\frac{\delta}{1+\delta} \frac{\bar{w}-\bar{y}-\tau \frac{\bar{H}}{N}}{1+p_{z}}+\frac{\overline{e_{1}}}{r}\right) N .
\end{aligned}
$$

Comparing $S$ with $Z^{D}$ in (37), we see that fee $\tau$, combined with the participation constraint, impacts on $Z^{D}$ and thus on the skill premium and the $(X, Z)$-structure like an increase of $\overline{e_{0}}$ to

$$
\tilde{e_{0}}=\overline{e_{0}}+\tau \frac{\bar{H}}{N} \text {. }
$$

Moreover, $\frac{F}{D}=\frac{s_{f} \bar{H}}{\frac{\left(y^{L}-\bar{y}\right) \bar{L}}{y^{H}-\bar{y}_{+}}+s_{d} \bar{H}+\frac{1+\delta}{\delta} \frac{\left(1+p_{z}\right) \bar{e}_{1}}{r} \frac{N}{y^{H}-\bar{y}_{+}}}$is declining in $\tau$. Thus, the participation constraint does not change the comparative static effects of fixed cost $\tau$ described in Proposition 8 .

The above conclusion is only valid if $\tau F$ is absorbed by real fixed cost requirements as discussed in Section 7.1. If $\tau F$ is a rent which is redistributed back to high-skilled agents, as in Section 7.2 , we have $\left(y^{H}-\bar{y}-\tau\right) \bar{H}+\tau \bar{H}=y^{H}-\bar{y}$ 
instead of $y^{H}-\bar{y}_{+}$so that

$$
\begin{aligned}
D & =\frac{\delta}{1+\delta} \frac{\bar{w}-\bar{y}}{1+p_{z}} N\left(1-s_{f} \beta_{H}\right)+\frac{\overline{e_{1}}}{r} N \\
F & =s_{f} \frac{\delta}{1+\delta} \frac{\bar{H}}{1+p_{z}}\left(y^{H}-\bar{y}\right) \\
S & =\left(\frac{\delta}{1+\delta} \frac{\bar{w}-\bar{y}}{1+p_{z}}+\frac{\overline{e_{1}}}{r}\right) N
\end{aligned}
$$

with $\beta_{H} \equiv \frac{y^{H}-\bar{y}}{\bar{w}-\bar{y}} \frac{\bar{H}}{N}$ denoting the income share of high-skilled agents. For the high-skilled nothing changes, but the low-skilled are only saving through $D$. This means that, compared to the benchmark, we have an increase in $D$ and a decrease in $F . Z^{D}=S$ coincides with the expression in (30) so that equilibrium skill premium and $(X, Z)$-structure are not changed compared to the baseline 18

For the within sectoral structure in the $Z$-sector, we have in the benchmark case with $p_{z_{1}}=p_{z_{2}}=p_{z}$ :

$$
\begin{aligned}
\frac{F}{D} & =\frac{s_{f} \beta_{H}}{1-s_{f} \beta_{H}+\frac{1+\delta}{\delta} \frac{1+p_{z}}{\bar{w}-\overline{\bar{y}}} \frac{\overline{e_{1}}}{r}} \\
& =\frac{s_{f} \beta_{H} \bar{\eta}}{s_{d} \bar{\eta}+s_{f}\left(1-\beta_{H}\right) \bar{\eta}+\frac{1+\delta}{\delta} \frac{\overline{e_{1}}}{r}} \equiv \tilde{\Phi}
\end{aligned}
$$

Comparing this with (33), we conclude that $\tilde{\Phi}<\Phi$ because $s_{f}\left(1-\beta_{H}\right)>0$. Yet, the proportion of total expenditure on new finance relative to expenditure on traditional finance $\frac{p_{z} F+\tau \bar{H}}{p_{z} D}=\frac{F}{D}+\frac{\tau \bar{H}}{p_{z} D}$ is ambiguous. Rent $\tau$ increases the new finance share, but the participation constraint induces a shift of the portfolio towards safe assets.

\footnotetext{
${ }^{18}$ For $p_{z_{1}} \neq p_{z_{2}}$, however, the change in $Z_{2}^{D}$ would also affect $\omega$ and all other equilibrium outcomes.
} 


\subsection{Set-up capital for firms}

In the baseline model invested capital is transformed by linear technologies, using capital as the only input, into future outcome. The extension in this section shows that the baseline can be seen as kind of reduced form of a richer model, in which capital is needed to set up firms. We assume now that firms in the $X$-sector use capital to set up technology $G^{x}$, which then produces output by employing low-skilled and high-skilled labor. Each established firm $\nu \in\{1, \ldots, M\}$ produces a variety $x_{\nu}=G^{x}\left(L_{x_{\nu}}, H_{x_{\nu}}\right)$ under monopolistic competition with free entry. Consumers spend the supernumerary income $e_{t}-\bar{e}_{t}$ according to a CES-utility function with substitution elasticity $\sigma>1$ symmetrically over the variants $x_{\nu}$ in the $X$-sector, which implies an instantaneous indirect utility function of the form $\log \left(e_{t}-\bar{e}_{t}\right)$ (see Section 7.5.1) like before. So saving decision and portfolio choice remain the same as in the baseline model. Firms have positive operating profits which are distributed as payoff to the investors (see Section 7.5.2).

\subsubsection{Consumer problem}

Let the instantaneous utility of households be given by $u=\left[\sum_{\nu=1}^{M} x_{\nu}^{\frac{\sigma-1}{\sigma}}\right]^{\frac{\sigma}{\sigma-1}}$, $\sigma>1$. Then, prices are determined by a constant markup on unit cost of production

$$
p_{\nu}=\frac{\sigma}{\sigma-1} c\left(w_{H}, w_{L}\right)
$$

where $c\left(w_{H}, w_{L}\right)$ are the unit costs (as in Section 21) and $w_{H}, w_{L}$ are factor prices. Moreover, demand for variety $x_{\nu}$ of a household that spends "super- 
numerary budget" $e-\bar{e}$ is

$$
x_{\nu}=(e-\bar{e}) \frac{p_{\nu}^{-\sigma}}{P^{1-\sigma}}, \quad P \equiv\left[\sum_{\nu=1}^{M} p_{\nu}^{1-\sigma}\right]^{\frac{1}{1-\sigma}} .
$$

Since product variants use identical production technologies, their unit cost and prices are identical, too. Thus, $x_{\nu}$ reduces to $x=\frac{e-\bar{e}}{p_{\nu} M}$. Using this in $u$, we obtain for the instantaneous indirect utility $u=\frac{e-\bar{e}}{P}$. We set the price as numéraire (i.e., $p_{\nu}=1$ ) so that the variety effect is $P=M^{\frac{1}{1-\sigma}}$. Due to the $\log$ specification, this variety effect, though affecting the level of utility, does not matter for the intertemporal decision 19 Thus, max $\mathbb{E} \log (u)=\max \mathbb{E} \log \left(e_{t}-\right.$ $\left.\bar{e}_{t}\right)$, which is identical to the intertemporal problem in Section 2.2 .

\subsubsection{Firm entry and production in the $X$-sector}

There are two types of set-up technologies, which induce capital demand of firms: A robust set-up technology which requires $c_{0}$ units of capital. Firms set up by the robust technology will be producing tomorrow under any condition (i.e., in $\Theta$ and $\bar{\Theta}$ ). Furthermore, there are risky set-up technologies with setup input $c_{\theta}$, which are only effective if state $\theta \in \Theta$ occurs. Otherwise, their set-up fails. In an analogous way to (1), we assume

$$
c_{\theta}=\pi_{\theta} c_{1} \text {, where } c_{1}<c_{0} .
$$

The assumption states that set-up capital required for a robust technology is larger than the capital required for risky technologies. Moreover, the smaller the measure $\pi_{\theta}$ of the state under which a set-up technology works, the lower the required set-up capital.20 Robust set-up technologies are financed by

\footnotetext{
${ }^{19}$ Note that $\log \frac{e-\bar{e}}{P}=\log (e-\bar{e})-\log P$ so that the $P$-levels add to $\mathbb{E} U$ a constant.

${ }^{20}$ See Falkinger (2014) for a more detailed discussion of the relationship between specialization and risk. There, technologies are more productive the more narrowly they are
} 
loans, whereas the risky set-up techniques are financed by state-contingent securities.

Let $K_{0}$ be the aggregate set-up capital for robust technologies and denote by $K_{\theta}, \theta \in \Theta$, the aggregate set-up capital for specialized risky technologies. Then the number of firms which can be set up is $M_{0}=\frac{K_{0}}{c_{0}}$ and $M_{\theta}=\frac{K_{\theta}}{c_{\theta}}$, respectively. In a closed economy, capital markets are cleared if

$$
K_{0}=D, \quad K_{\theta}=F_{\theta}=\pi_{\theta} F .
$$

Hence, we have for to total number of firms

$$
M= \begin{cases}\frac{D}{c_{0}}+\frac{F}{c_{1}} \equiv M_{\Theta}, & \text { if } \theta \in \Theta \\ \frac{D}{c_{0}} \equiv M_{\bar{\Theta}} & \text { otherwise }\end{cases}
$$

After firms being set up, their operating profits earned under mark-up prices (47) are

$$
\Pi=\left(p_{x}-c\right) X=\frac{X}{\sigma},
$$

where $p_{x}=1$, which implies $c=\frac{\sigma-1}{\sigma}$, has been used. Since firms are symmetric, aggregated operating profits are distributed uniformly across firms so that operating profit per firm is:

$$
\frac{\Pi_{m}}{M_{m}}=\frac{X}{\sigma M_{m}}, m \in\{\Theta, \bar{\Theta}\} .
$$

targeted to a specific environment. At the same time, they are more risky because the realization of the specific environment is less likely. Here this idea is applied to set-up costs rather than productivity. 
The returns on one unit of set up capital are therefore

$$
\begin{aligned}
& r_{m}=\frac{X}{c_{0} \sigma M_{m}}, m \in\{\Theta, \bar{\Theta}\} \\
& R_{\theta}=\frac{X}{c_{\theta} \sigma M_{\Theta}}, \quad R=\frac{X}{c_{1} \sigma M_{\Theta}}
\end{aligned}
$$

for safe and risky investments, respectively. $\left(\pi_{\theta} R_{\theta}\right.$ reduces to $R$ because of assumption $c_{\theta}=\pi_{\theta} c_{1}$.) Since the number of firms is different in $\Theta$ and $\bar{\Theta}$, aggregate operating profits have to be shared among more or less firms so that the return on robust investments is $m$-dependent. The relative rate of return, $\frac{r_{\Theta}}{R_{\theta}}$, however, is uniquely determined by the relative set-up requirements of specialized risky technologies compared to the robust technology. We have

$$
\rho=\frac{c_{1}}{c_{0}}
$$

For the portfolio choice derived in Section 4 almost only the relative rate $\rho$ matters. The exception is $\frac{\bar{e}_{1}}{r_{m}}$, since future subsistence can only be financed by deposits 21 This means, we have to restrict the analysis of the paper to $\bar{e}_{1}=0$, or we reconcile the fluctuation of the earnings of robust firms with a safe return on deposits by assuming that firms hold buffers and distribute the expected profit per firm $\bar{\pi} \equiv\left[\frac{\mu}{M_{\Theta}}+\frac{1-\mu}{M_{\bar{\Theta}}}\right] \frac{X}{\sigma}$ to the investors.

For the general equilibrium analysis, a further caveat is in order. Under the presented extension, return $r$ (even if smoothed by the buffer) is endogenous. It depends on $M$ and $X$, which are determined by saving behavior and resource allocation, respectively. Thus, in the general equilibrium, a further

\footnotetext{
${ }^{21}$ Formally the derivation of the portfolio choice presented in the appendix has to be adapted to account for $m$-dependent pay-offs in the budget constraints. For $\bar{e}_{1}=0$, return $r_{\bar{\Theta}}$ becomes irrelevant under the logarithm specification and the analysis remains valid with $\rho=\frac{r_{\Theta}}{R_{\Theta}}$.
} 
feedback loop is to be considered. We did not account for such feedbacks in Section 6, since in the baseline return $r$ is exogenously given by the constant productivity of capital. For $\bar{e}_{1}=0$, however, the presented analysis remains fully valid also with set-up capital of firms, since $r$ matters only through the term $\frac{\bar{e}_{1}}{r}$. However, what one loses by setting $\bar{e}_{1}=0$ is the income effect on structural change within the financial sector. For the income effect on the skill premium and the structural change between goods and financial sector subsistence level $\bar{e}_{0}>0$ is relevant, which poses no problem in the extension considered here.

\section{Robustness}

To account for relative price effects within the financial sector, we skip now Assumption 2 and impose the following restriction instead.

Assumption 2'. $\alpha_{x}=\alpha_{z_{1}}<\alpha_{z_{2}}$.

Then, according to (12),

$$
p_{z_{1}}=\frac{A_{x}}{A_{z_{1}}}
$$

and thus: $\bar{y}=\overline{e_{0}}+\frac{\left(1+\frac{A_{x}}{A_{z_{1}}}\right) \overline{e_{1}}}{r}$.

Moreover, the terms $a_{x}^{l} X+a_{z_{1}}^{l} Z_{1}, l \in\{H, L\}$, in system (13) reduce to

$$
X^{+} \frac{1}{A_{x} \kappa_{x}^{\alpha_{x}}} \text { and } X^{+} \frac{\kappa_{x}^{\left(1-\alpha_{x}\right)}}{A_{x}}, X^{+} \equiv X+\frac{A_{x}}{A_{z_{1}}} Z_{1},
$$

respectively. Using this when solving (13), we obtain

$$
X^{+}=\frac{b_{L} \bar{L}}{a_{x}^{L}} \frac{\kappa_{z_{2}}-k}{\kappa_{z_{2}}-\kappa_{x}}, Z_{2}=\frac{b_{L} \bar{L}}{a_{z_{2}}^{L}} \frac{k-\kappa_{x}}{\kappa_{z_{2}}-\kappa_{x}}
$$


and

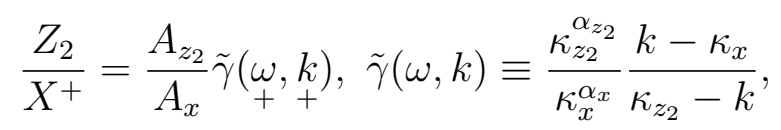

where the signs for the partial derivatives of $\tilde{\gamma}$ follow from the Rybczynski analysis.

Substituting $A_{z_{2}} \kappa_{z_{2}}^{\alpha_{z_{2}}}$ for $\frac{1}{a_{z_{2}}^{L}}$ in the second equation of (49) and using (91), we have for the $Z_{2}$-supply:

$$
Z_{2}^{S}=A_{z_{2}} b_{L} \bar{L} \frac{\gamma_{z_{2}}^{\alpha_{z_{2}}}}{\gamma_{z_{2}}-\gamma_{x}} g(\underset{+}{\omega}, k), g(\omega, k) \equiv \omega^{-\alpha_{z_{2}}}\left(k \omega-\gamma_{x}\right)
$$

This coincides with (40) - with $Z_{2}$ instead of $Z$ - so that Fact 6 remains valid under the alternative specification and applies to $Z_{2}$-supply.

$Z_{2}$-demand is given by

$$
Z_{2}^{D}=F=s_{f} \frac{\delta}{1+\delta} \frac{\bar{w}-\bar{y}}{1+p_{z_{2}}} N=\frac{\mu-\rho p}{1-\rho p} \frac{\delta}{1+\delta} \tilde{\eta} N
$$

with $\tilde{\eta} \equiv \frac{\bar{w}-\bar{y}}{1+p_{z_{2}}}$ and $p=\frac{1+p_{z_{2}}}{1+p_{z_{1}}}$. In an analogous way to Lemma 1 and Fact 7, one establishes that the income effect (i.e., $\tilde{\eta}$-part in $Z_{2}^{D}$ ) has an U-shaped form 22 Further, $s_{f}$ is decreasing in $\omega$ since $\frac{\partial p}{\partial \omega}>0$ (according to (12)). Because of the relative price effect $p$, which now is at work within the finance sector, the demand for risky assets is substituted by demand for safe assets if the relative price of services for securities rises. For low values of the skill premium, we are on the downward sloping branch of the $\tilde{\eta}$-curve so that income and substitution effect go in the same direction. In the upward sloping part of $\tilde{\eta}$, the negative substitution effect is opposed by a positive income effect so that the total effect of $\omega$ on $Z_{2}^{D}$ depends on the

\footnotetext{
${ }^{22}$ The only thing that changes is that now we have $\frac{\bar{y}}{1+p_{z_{2}}}$ with $\bar{y}$ constant instead of $\frac{\bar{y}}{1+p_{z_{1}}}=\frac{\overline{e_{0}}}{1+p_{z_{1}}}-\frac{\overline{e_{1}}}{r}$. Thus, apart from subscript $z_{2}$ instead of $z\left(=z_{1}=z_{2}\right)$ in the modified proof we have $\bar{y}$ instead of $\overline{e_{0}}$ and no negative term $-\frac{\overline{e_{1}}}{r}$.
} 
relative importance of the two effects. Numerical simulation shows that the substitution effect is large if the price $p_{z_{2}}$ is high and the income effect is stronger if subsistence expenditures are larger. For a high level of price $p_{z_{2}}$ (based on (12) this means, for example, a low $A_{z_{2}}$ ) and low subsistence levels (such that $\bar{y}$ is close to zero) the substitution effect dominates. In this case $\frac{\partial Z_{2}^{D}}{\partial \omega}<0$. However, for low levels of price $p_{z_{2}}$ and large subsistence levels the income effect dominates. For this case, (51) and (52) give us the same picture as in Figure 1. Proposition 4 remains valid in both cases.

For Proposition 5, we have to write the excess demand function $Z_{2}^{D}-Z_{2}^{S}$ explicitly in terms of parameters. Using $W=b_{L} \bar{L} A_{x} \Gamma_{x} \omega^{-\alpha_{x}}(1+\omega k)$ and $p_{z_{2}}=\frac{A_{x} \Gamma_{x}}{A_{z_{2}} \Gamma_{z_{2}}} \omega^{\alpha_{z_{2}}-\alpha_{x}}$ in (52), we can rewrite the equilibrium condition $Z_{2}^{D}-$ $Z_{2}^{S}=0$ in the form:

$$
\begin{aligned}
& \frac{\mu-\rho \frac{1+\frac{A_{x} \Gamma x}{A_{z_{2}} \Gamma_{z_{2}}} \omega^{\alpha_{z_{2}}-\alpha_{x}}}{1+p_{z_{1}}}}{1-\rho \frac{1+\frac{A_{x} \Gamma_{x}}{A_{z_{2}} \Gamma_{2}} \omega^{\alpha_{z_{2}}-\alpha_{x}}}{1+p_{z_{1}}}} \frac{\delta}{1+\delta} \frac{\Gamma_{x} \omega^{-\alpha_{x}}(1+\omega k)-\frac{N}{b_{L} \bar{L} A_{x}} \bar{y}}{1+\frac{A_{x} \Gamma_{x}}{A_{z_{2}} \Gamma_{z_{2}}} \omega^{\alpha_{z_{2}}-\alpha_{x}}} \\
& -\frac{A_{z_{2}}}{A_{x}} \frac{\gamma_{z_{2}}^{\alpha_{z_{2}}}}{\gamma_{z_{2}}-\gamma_{x}} \omega^{-\alpha_{z_{2}}}\left(k \omega-\gamma_{x}\right)
\end{aligned}
$$

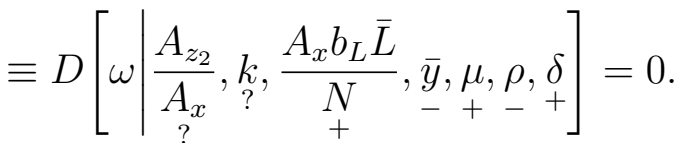

Hence, an increase of $\frac{A_{x} b_{L} \bar{L}}{N}$ always leads to a rise in the equilibrium skill premium. Under Assumption 2, this was only the case if present subsistence expenditure dominates futures subsistence requirements (Proposition 51). Moreover, a decline in subsistence requirements $\bar{y}$ has unambiguously a positive impact on the equilibrium skill premium - regardless of whether the decline in $\bar{y}$ is caused by a decline in $\overline{e_{0}}$ or $\overline{e_{1}}$.

In contrast to the benchmark analysis, the equilibrium skill premium is now 
also affected by changes in $\mu$ and $\rho$. Finally, a rise in $\delta$ has now an unambiguously positive effect on $\omega^{*}$. (In the benchmark analysis the role of $\delta$ was ambiguous.) The following proposition summarizes the comparative-static effects on the equilibrium skill premium under Assumption 2'.

Proposition 5'. If Assumption 2 is replaced by Assumption 2', then:

a) For $\bar{y}>0$, a rise in $\frac{A_{x} b_{L} \bar{L}}{N}$ (caused by uniform technical progress or education and biased progress) raises the equilibrium skill premium. A decline of total subsistence requirements $\bar{y}$ (wherever they come from) have the same effect.

b) Financial innovations (a rise in $\mu$ ) or increased attractiveness of risky investments (a decline of $\rho$ ) raise the equilibrium skill premium. A lower discount on the future (a rise of $\delta$ ) has the same effect. These effects also hold if $\bar{y}=0$.

Proof. Main text.

As a consequence of (50), Proposition 6 remains valid if applied to the structure between new finance on the one side and production cum traditional finance on the other side. We have

Proposition 6'. At given $\frac{A_{z}}{A_{x}}, k$, any change in other exogenous fundamentals which raises the skill premium leads to structural change from production and traditional finance $\left(X^{+}\right)$towards new finance $\left(Z_{2}\right)$.

Proof. Equation (50) and $\frac{\partial p_{z_{2}}}{\partial \omega}>0$. 
Finally, the ratio of value-added in financial sub-sector $Z_{2}$ to value-added in sub-sector $Z_{1}$ is as in (33)

$$
\frac{p_{z_{2}} F}{p_{z_{1}} D}=\frac{s_{f} \bar{\eta}}{s_{d} \bar{\eta}+\frac{1+\delta}{\delta} \frac{e_{1}}{r}} \frac{p_{z_{2}}}{1+p_{z_{2}}} \frac{1+p_{z_{1}}}{p_{z_{1}}} .
$$

Since $p_{z_{1}}$ and $\bar{y}$ are constant, $\frac{\partial \bar{w}}{\partial \omega}>0$ immediately implies $\frac{\partial \bar{\eta}}{\partial \omega}>0$. Hence, for $\bar{e}_{1}>0$, the income effect unambiguously leads to structural change from $Z_{1}$ to $Z_{2}$ if the skill premium rises. If $\bar{e}_{1}=0$, no such income effect is at work; yet the relative price effect remains. For the relative price effect, we only have to consider $p_{z_{2}}$ because $p_{z_{1}}$ is constant. Price $p_{z_{2}}$ affects the value added structure within finance through two channels: On the one side, there is the direct effect shown explicitly in (153). Since $\frac{\partial p_{z_{2}}}{\partial \omega}>0$, this channel tends to increase the share of new finance. On the other side, however, there is the negative substitution effect in the demand for financial services $\left(\frac{\partial s_{f}}{\partial p}<0\right.$ and $\left.\frac{\partial s_{d}}{\partial p}>0\right)$ which drives the sectoral structure within finance from $Z_{2}$ towards $Z_{1}$. Due to this ambiguous role of the relative price effect under the alternative specification, within structural change from $Z_{1}$ to $Z_{2}$ is more difficult to model than it was in the benchmark. For high levels of price $p_{z_{2}}$ and low subsistence expenditures the substitution effect dominates. Then, the presented model cannot predict a co-movement of $\omega$ and the within structural change from $Z_{1}$ to $Z_{2}$. In the other case, however, Proposition (7) applies.

\section{Empirical evidence and numerical exercises}

In this section we first provide empirical evidence on the two-fold structural change and on wage inequality and then we carry out numerical exercises to 
show how our model can replicate the observed changes.

\subsection{Empirics}

\subsubsection{Data}

We use data from the March Current Population Survey (CPS) for the years 1980-2014. This data set allows us to split the sampled population (weighted with the sampling weight) into our three sectors and two skill levels: The $X$ sector consists of all sectors of the U.S. economy except finance. The finance sector is finance and insurance without real estate 23 "Traditional finance" $Z_{1}$ includes banking and related activities, savings institutions, including credit unions, non-depository credit and related activities, and insurance carriers and related activities. "New finance" $Z_{2}$ is securities, commodities, funds, trusts, and other financial investments. We define a worker (if working) to be high-skilled if she/he holds a college degree or more. Then, $\bar{H}_{j}$ is the number of high-skilled workers in sector $j \in\left\{x, z_{1}, z_{2}\right\}$ and $\bar{L}_{j}$ is the number of lowskilled workers in sector $j \in\left\{x, z_{1}, z_{2}\right\}$. For each skill level, we calculate for the three sectors average yearly hours worked (i.e., $h_{j}^{l}, j \in\left\{x, z_{1}, z_{2}\right\}, l \in$ $\{H, L\})$ and the respective average hourly real wages (i.e., $w_{j}^{l}, j \in\left\{x, z_{1}, z_{2}\right\}$, $l \in\{H, L\})$.

In our data analysis we use "actual" and "normalized" numbers for employment and wage levels. The "actual" numbers use the observed sector- and skill-specific average yearly hours worked and the respective average hourly

\footnotetext{
${ }^{23}$ This corresponds to the standard classification as in Philippon and Reshef (2007, 2012).
} 
wage. The "normalized" numbers are calculated all with the same basis of hours worked and hourly wage (i.e., the ones from the $X$-sector) 24 The normalization allows us to separate the effects we can identify in the theoretical, frictionless model from two frictions observed in reality: (i) Low- and high-skilled $Z$-workers work more hours per year than low- and high-skilled $X$-workers. More precisely, for the U.S. over the last decades on average a $Z$-worker has worked about $9 \%$ more than a $X$-worker. (ii) There is the finance premium on hourly wages for low- and high-skilled $Z$-workers 25 CPS data show that the finance premium increased over time and differs for the two sub-sectors: In $Z_{1}$ workers earn about $15 \%$ more than in the $X$-sector, in $Z_{2}$ it is even $50 \%$.

The sectoral structure-figures below show black and gray lines: The gray lines correspond to the "actual" numbers. The black lines correspond to the "normalized" ones.

\subsubsection{Empirical trends}

As is described in the introduction and picked up in the model, financialization has several aspects: On the one hand, the weight of the financial sector relative to non-financial business has increased; this is structural change towards finance. On the other hand, the type of financial products and services has changed; this is structural change within finance. The next two figures

\footnotetext{
${ }^{24}$ Since the skill premium is approximately identical in all three sectors in the U.S. the skill intensities in the sectors need not be "normalized". They already correspond to the frictionless numbers.

${ }^{25}$ See Célérier and Vallée (2015) or Philippon and Reshef (2007, 2012) for a detailed empirical discussion of the finance premium.
} 
show the two-fold structural change.

Figure 2 shows the ratio of the total finance sector ( $Z$-sectors) compared to the non-finance economy ( $X$-sector) for the U.S. based on the CPS data. On the one hand, the figure shows that finance has attracted new employment. The employment ratio (in terms of total hours worked) of the financial sector, defined by $\Psi_{\text {actual }}^{E} \equiv \frac{h_{z_{1}}^{H} \bar{H}_{z_{1}}+h_{z_{2}}^{H} \bar{H}_{z_{2}}+h_{z_{1}}^{L} \bar{L}_{z_{1}}+h_{z_{2}}^{L} \bar{L}_{z_{2}}}{h_{x}^{H} \bar{H}_{x}+h_{x}^{L} \bar{L}_{x}}$, increased from $4.8 \%$ in 1980 to $5.6 \%$ in 2014 . The respective "normalized" ratio $\Psi_{\text {normalized }}^{E} \equiv$ $\frac{h_{x}^{H} \bar{H}_{z_{1}}+h_{x}^{H} \bar{H}_{z_{2}}+h_{x}^{L} \bar{L}_{z_{1}}+h_{x}^{L} \bar{L}_{z_{2}}}{h_{x}^{H} \bar{H}_{x}+h_{x}^{L} \bar{L}_{x}}$ rose from $4.6 \%$ in 1980 to $5.1 \%$ in 2014 . On the other hand, the figure illustrates the structural change towards the financial sector in terms of a growing wage sum ratio of finance. The wage sum ratio of the financial sector, defined as $\Psi_{\text {actual }} \equiv \frac{w_{z_{1}}^{H} h_{z_{1}}^{H} \bar{H}_{z_{1}}+w_{z_{2}}^{H} h_{z_{2}}^{H} \bar{H}_{z_{2}}+w_{z_{1}}^{L} h_{z_{1}}^{L} \bar{L}_{z_{1}}+w_{z_{2}}^{L} h_{z_{2}}^{L} \bar{L}_{z_{2}}}{w_{x}^{H} h_{x}^{H} \bar{H}_{x}+w_{x}^{L} h_{x}^{L} \bar{L}_{x}}$, increased by $55 \%$ from about $5.1 \%$ in 1980 to $7.9 \%$ in 2014 . The respective "normalized" ratio $\Psi_{\text {normalized }} \equiv \frac{w_{x}^{H} h_{x}^{H} \bar{H}_{z_{1}}+w_{x}^{H} h_{x}^{H} \bar{H}_{z_{2}}+w_{x}^{L} h_{x}^{L} \bar{L}_{z_{1}}+w_{x}^{L} h_{x}^{L} \bar{L}_{z_{2}}}{w_{x}^{H} h_{x}^{H} \bar{H}_{x}+w_{x}^{L} h_{x}^{L} \bar{L}_{x}}$ rose by $23 \%$ from $4.7 \%$ in 1980 to $5.8 \%$ in 2014 . The difference between the employment $(E)$ ratio and the wage sum ratio is the result of different skill-intensities in the different sectors. By comparing the "normalized" black with the "actual" gray lines one sees a large difference between the two ratios of the wage sum: More than half of the increase in the ratio of the wage sum is the result of the frictions (i) and (ii). Yet, as the black line shows, there is still structural change towards finance if one controls for the two frictions. Comparison of the two black lines shows that the difference between the employment ratio and the wage sum ratio increased over time. 


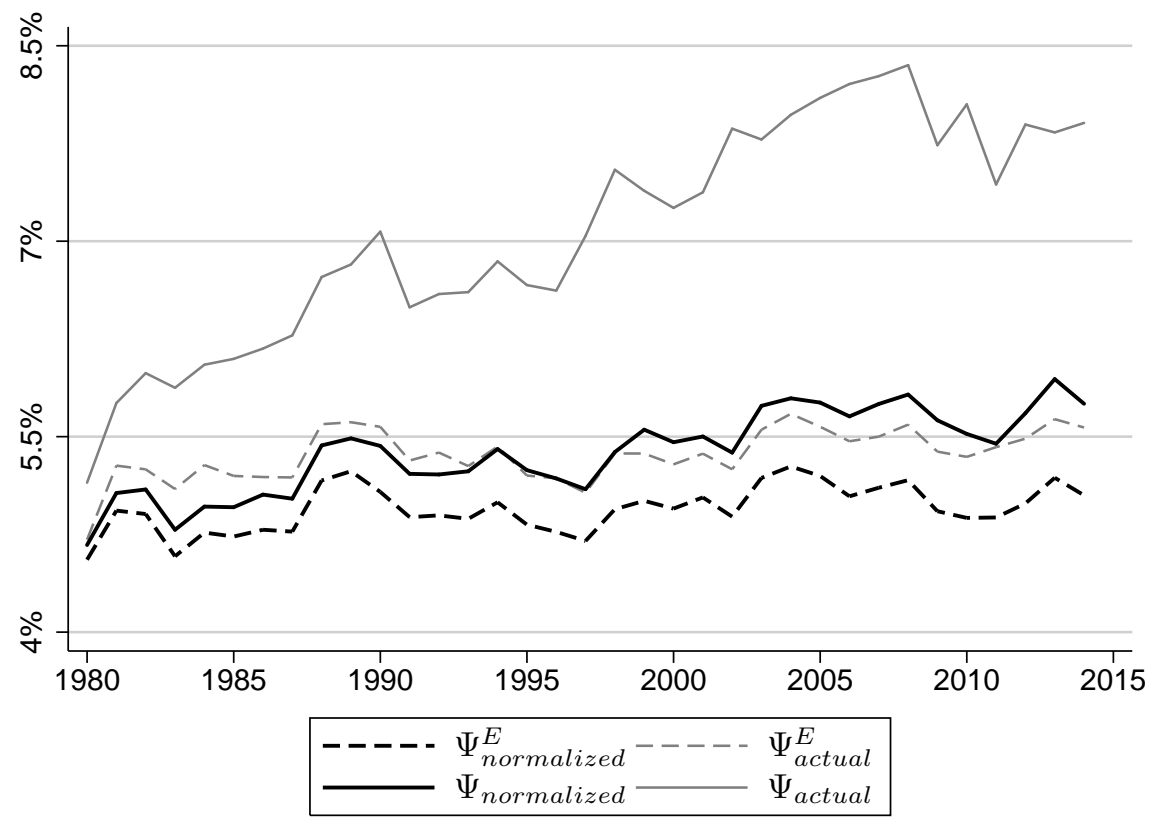

Figure 2: Employment ratio and wage sum ratio of the financial sector

Notes: $\Psi^{E}$ measures the employment ratio (in terms of total hours worked) of finance (including insurance) compared to the rest of the U.S. economy. $\Psi$ measures the ratio of the total wage sum in finance vs. the rest of the U.S. economy. "Actual" uses the observed sector-specific hours worked and hourly wages (for low-and high-skilled), whereas "normalized" uses the $X$-sector hours worked and hourly wages (for low-and high-skilled). Data from 1980-2014. Source: March CPS.

We observe a similar pattern for the within finance sectoral structure by splitting total finance up into sub-sectors $Z_{1}$ and $Z_{2}$. Figure 3 shows the employment ratio and the wage sum ratio of finance sub-sector $Z_{2}$ compared to the sub-sector $Z_{1}$ for the U.S. since the eighties based on the CPS data set. "New finance" (sub-sector $Z_{2}$ ) grew strongly independent of the measure we use: The within employment ratio (in terms of total hours worked) of finance sub-sector $Z_{2}, \Phi_{\text {actual }}^{E} \equiv \frac{h_{z_{2}}^{H} \bar{H}_{z_{2}}+h_{z_{2}}^{L} \bar{L}_{z_{2}}}{h_{z_{1}}^{H} \bar{H}_{z_{1}}+h_{z_{1}}^{L} \bar{L}_{z_{1}}}$, more than doubled from about $8.8 \%$ in 1980 to $19.6 \%$ in 2014 . The respective "normalized" ratio $\Phi_{\text {normalized }}^{E} \equiv$ 
$\frac{h_{x}^{H} \bar{H}_{z_{2}}+h_{x}^{L} \bar{L}_{z_{2}}}{h_{x}^{H} \bar{H}_{z_{1}}+h_{x}^{L} \bar{L}_{z_{1}}}$ is very similar with a rise from $8.6 \%$ in 1980 to $19.6 \%$ in 2014 . The within finance wage sum ratio, defined by $\Phi_{\text {actual }} \equiv \frac{w_{z_{2}}^{H} h_{z_{2}}^{H} \bar{H}_{z_{2}}+w_{z_{2}}^{L} h_{z_{2}}^{L} \bar{L}_{z_{2}}}{w_{z_{1}}^{H} h_{z_{1}}^{H} \bar{H}_{z_{1}}+w_{z_{1}}^{L} h_{z_{1}}^{L} \bar{L}_{z_{1}}}$, increased dramatically from $11 \%$ in 1977 to $29.5 \%$ in 2012 peaking in 2009 at $40.2 \%$. The respective "normalized" ratio $\Phi_{\text {normalized }} \equiv \frac{w_{x}^{H} h_{x}^{H} \bar{H}_{z_{2}}+w_{x}^{L} h_{x}^{L} \bar{L}_{z_{2}}}{w_{x}^{H} h_{x}^{H} \bar{H}_{z_{1}}+w_{x}^{L} h_{x}^{L} \bar{L}_{z_{1}}}$ rose from $9.3 \%$ in 1980 to $22.8 \%$ in 2014 with a peak in 2009 of $29.9 \%$. Hence, about two-thirds of the actual rise in the wage ratio of "new finance" cannot be assigned to frictions: They are also observed in the "normalized" data. The rest of the rise comes from friction (ii) (finance premium), which is particularly strong in the finance sub-sector $Z_{2}$.

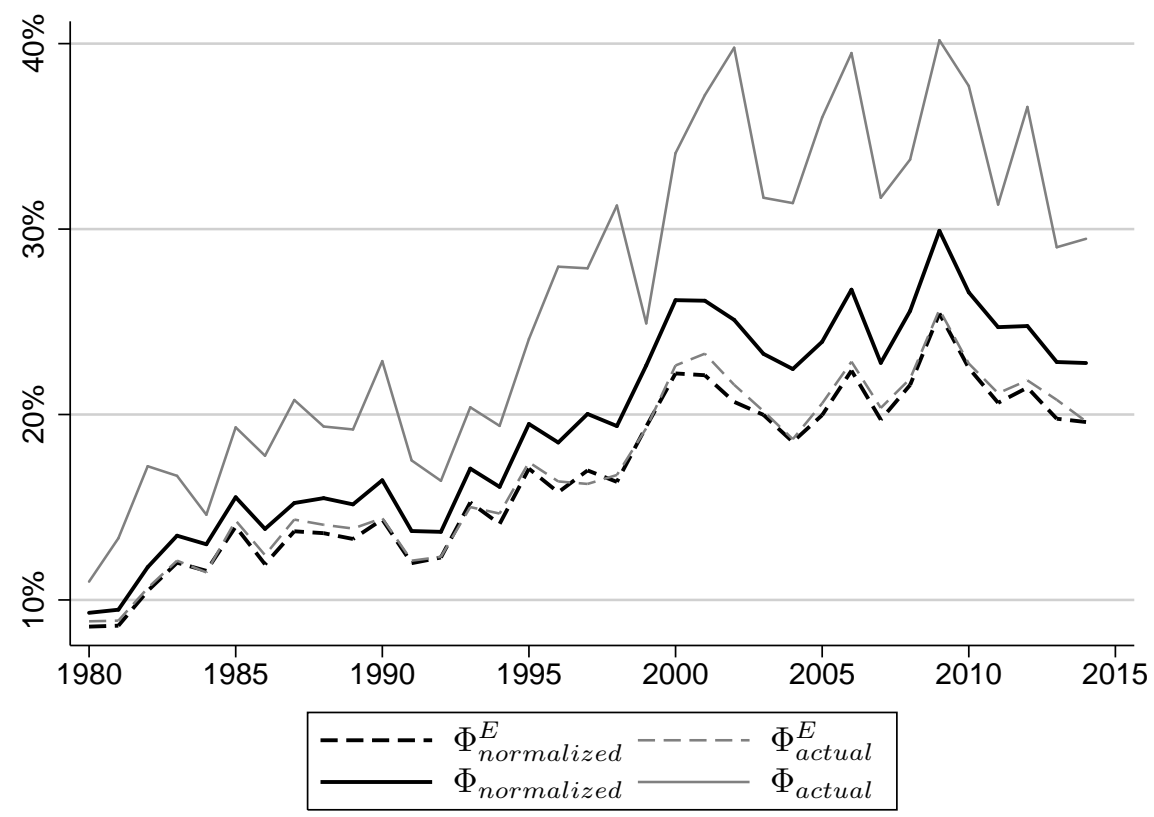

Figure 3: Employment ratio and wage sum ratio within the financial sector

Notes: $\Phi^{E}$ measures the employment ratio (in terms of total hours worked) of "new finance" compared to "traditional finance". $\Phi$ measures the ratio of the total wage sum in "new finance" vs. "traditional finance". "Actual" uses the sector-specific hours worked and hourly wages (for low-and high-skilled), whereas "normalized" uses the $X$-sector hours worked and hourly wages (for low-and high-skilled). Data from 1980-2014. Source: March CPS. 
As argued in the introduction financialization (with the two-fold structural change) and inequality are two closely related topics. Figure 4 shows the development of the "normalized" skill premium calculated by $\omega=\frac{w_{x}^{H}}{w_{x}^{L}}$ for the U.S. since 1980, based on the CPS data. It increased from 1.46 to 1.91 in 2014.26 The time trend in $\omega$ illustrates that wage inequality increased over time. Nowadays high-skilled workers earn nearly double as much as low-skilled workers per hour. If one accounts in addition for the fact that high-skilled workers work more hours, the income inequality is even larger (e.g., 2.15 in 2014).

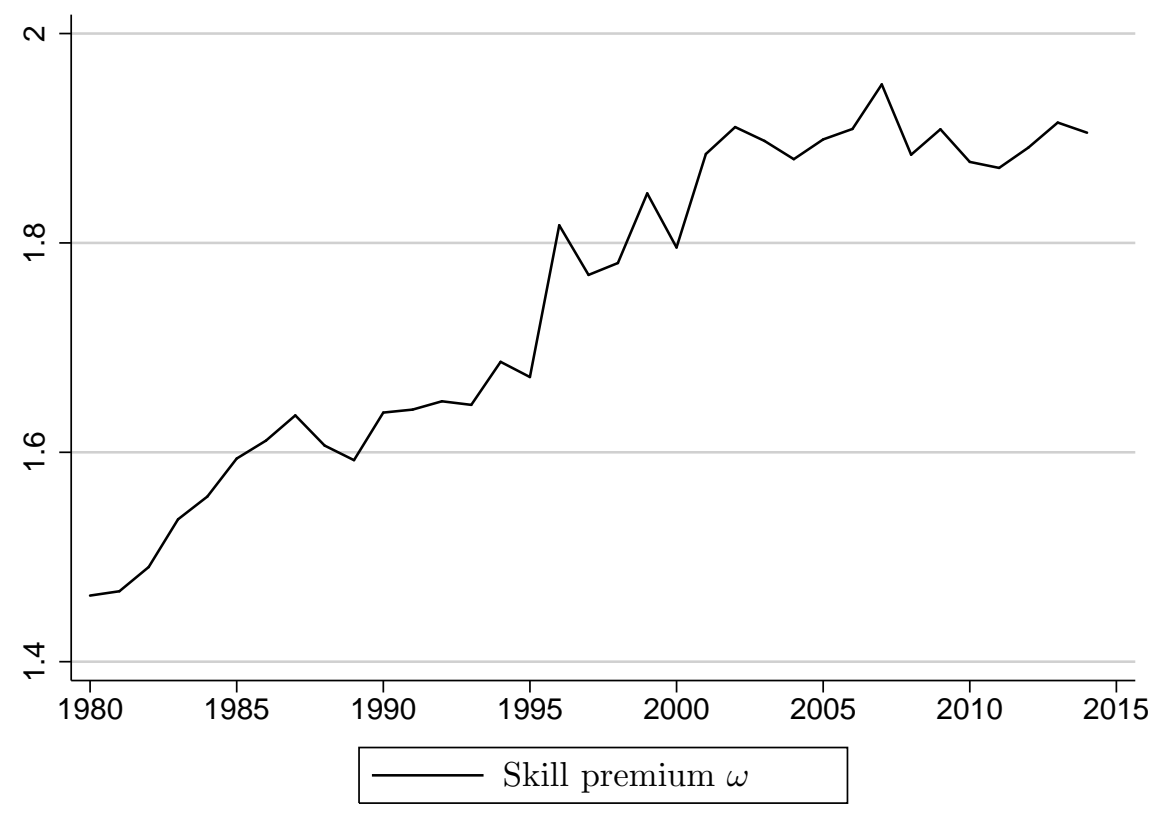

Figure 4: Skill premium

Notes: $\omega$ measures the "normalized" skill premium (i.e., hourly wage of high-skilled labor in $X$-sector divided by hourly-wage of low-skilled labor in $X$-sector). Data from 1980-2014. Source: March CPS.

\footnotetext{
${ }^{26}$ Interestingly, the skill premium in the U.S. is about the same in the three sectors because both low- and high-skilled workers who work in the financial industry earn a similar relative finance premium.
} 


\section{$9.2 \quad$ Numerics}

In this section we implement our theoretical model quantitatively and use it for several numerical exercises. These illustrate possible drivers of the empirical developments presented in Figures 2,4. First, we calibrate our model for the average values of the early years (1980-1994) of the observed time span. This calibrated model is then used for comparative static analysis. We shock it (i) by ceteris paribus shocks and (ii) by simultaneous shocks to illustrate how the channels analyzed in our model can generate the situation observed in later years (average values of 1995-2009).

\subsubsection{Calibration}

We calibrate our model such that it fits the data for the average year from the time range 1980-1994. Exogenous values from data are used for labor endowments $\bar{L}, \bar{H}, h^{L}, h^{H}$, output elasticities $\alpha_{j}$, technology in the $X$-sector $A_{x}$, interest rate $r^{f}$ and poverty thresholds $\left(P T_{65}\right.$ for young and $P T^{65}$ for old households) as summarized in Table 1. For the subsistence levels we assume that each worker must cover over the life cycle half of a two-people household's poverty threshold. Further, we account for the fact that during the 1980-1994 time period the ratio of working-time to retirement was LEratio $=4.61$ (i.e., we divide the poverty threshold of old households by 4.61). Hence, $\bar{e}_{0}=P T_{65} / 2$ and $\bar{e}_{1}=P T^{65} / 2 / 4.61$. The real safe return is $r=1+r^{f}$ with $r^{f}$ being the Feds fund rate minus inflation and the risky return is such that the risk premium is four percentage points (i.e., $R=(r+0.04) / \mu)$. We measure the efficiency units from the model by $b_{l}=h^{l}, l \in\{H, L\}$, where $h^{l}$ are hours worked. 
Table 1: Parameters 1980-1994

\begin{tabular}{lcll}
\hline Parameter & Data & Source & Description \\
\hline $\bar{L}$ & $95.4 \mathrm{~m}$ & CPS & \# Low-skilled employees \\
$\bar{H}$ & $26.2 \mathrm{~m}$ & CPS & \# High-skilled employees \\
$h^{L}$ & 1675.1 & CPS & Yearly hours of low-skilled \\
$h^{H}$ & 2000.8 & CPS & Yearly hours of high-skilled \\
$\alpha_{x}$ & 0.33 & CPS & Output ela. of high-skilled in $X$ \\
$\alpha_{z_{1}}$ & 0.41 & CPS & Output ela. of high-skilled in $Z_{1}$ \\
$\alpha_{z_{2}}$ & 0.67 & CPS & Output ela. of high-skilled in $Z_{2}$ \\
$A_{x}$ & 34.92 & CPS & Technology level in $X$ \\
$P T_{65}$ & $\$ 15,564$ & U.S. Dep. of commerce & Real poverty threshold $<65$ \\
$P T^{65}$ & $\$ 13,996$ & U.S. Dep. of commerce & Real poverty threshold $>65$ \\
$L E r a t i o$ & 4.61 & LE from World Bank & Old-age ratio \\
$r^{f}$ & 3.33 & St.Louis Fed & Real Feds fund rate \\
\hline$A_{z_{1}}$ & 149 & Model calibration & Technology level in $Z_{1}$ \\
$A_{z_{2}}$ & 201 & Model calibration & Technology level in $Z_{2}$ \\
$\delta$ & 0.375 & Model calibration & Discount rate \\
$\mu$ & 0.750 & Model calibration & Certainty measure \\
\hline
\end{tabular}

Notes: The figures are the averaged values for the time range $t=1980-1994$ of: $\alpha_{j, t}=\frac{\kappa_{j, t} \omega_{j, t}}{1+\kappa_{j, t} \omega_{j, t}}$ with $\kappa_{j, t}=\frac{h_{j, t}^{H} \bar{H}_{j, t}}{h_{j, t}^{L} \bar{L}_{j, t}}$ and $\omega_{j, t}=\frac{w_{j, t}^{H}}{w_{j, t}^{L}}, j \in\left\{x, z_{1}, z_{2}\right\}, h_{t}^{H}=h_{x, t}^{H}$ and $h_{t}^{L}=h_{x, t}^{L} . \quad A_{x, t}=\frac{w_{x, t}^{L}}{\Gamma_{x, t} \omega_{x, t}^{-\alpha_{x, t}}}$ with $\Gamma_{x, t}=\alpha_{x, t} \alpha_{x, t}^{\alpha_{x}}\left(1-\alpha_{x, t}\right)^{1-\alpha_{x, t}} . \quad P T$ is the real poverty threshold of a two-people household (nominal values are adjusted by CPI-URS-inflation) with $P T_{65}$ denoting the relevant value for households younger than 65 and $P T^{65}$ denoting the value relevant for older ones. LEratio is the ratio of workingtime to retirement: $(65-20) /(L E-65)$, where $L E$ denotes life expectancy; 65 is the retirement age and 20 is the assumed start of the working-life. $r^{f}$ is the real Feds fund rate (Feds fund rate minus CPI-U-RS-inflation). CPI-U-RS-inflation data from U.S. Dep. of labor. 
The other parameters (productivities in the finance sectors $A_{z_{1}}$ and $A_{z_{2}}$, discount factor $\delta$ and completeness measure $\mu$ ) are calibrated internally by targeting wage inequality $\omega$, "normalized" ratios for the sectoral structure $\Psi$ and $\Phi$ of the U.S. economy and the gross saving rate in the U.S. for the average of the years 1980-1994. The targeted values are shown in Table 2. More specifically, we solve the model numerically for possible parameter combinations of $A_{z_{1}}, A_{z_{2}}, \delta$ and $\mu$ and grid-search for the combination (see Table1for calibrated values) which minimizes the sum of the squared relative distances of the four model values from the corresponding data targets 27 The four model values generated by our calibrated model are given in Table 2 ;

Table 2: Targets

\begin{tabular}{lccll}
\hline Variables & Model & Data & Source & Description \\
\hline$\omega^{*}$ & 1.54 & 1.59 & CPS & Skill premium \\
$\Psi$ & $5.14 \%$ & $5.14 \%$ & CPS & Between sectoral structure \\
$\Phi$ & $13.96 \%$ & $13.95 \%$ & CPS & Within sectoral structure \\
saving rate & $19.92 \%$ & $19.92 \%$ & World Bank & Aggregate savings \\
\hline
\end{tabular}

Notes: $\omega^{*}$ is the equilibrium skill premium (per hour worked). $\Psi$ corresponds to $\frac{p_{z_{1}} D+p_{z_{2}} F}{X}$ in the model and to $\Psi_{\text {normalized }}$ in the data. $\Phi$ corresponds to $\frac{p_{z_{1}} D}{p_{z_{2}} F}$ in the model and to $\Phi_{\text {normalized }}$ in the data. The saving rate is $(D+F) / W$ in the model and the share of aggregate savings in gross national income in the data, where aggregate savings (gross savings) is gross national income less total consumption, plus net transfers.

\footnotetext{
${ }^{27}$ For solving the model numerically, we use the demand functions in the goods and financial services markets to obtain the equilibrium values of $X-, Z_{1^{-}}$and $Z_{2}$ as functions of $\omega$ (and exogenous parameters). Substituting these functions for $X-, Z_{1^{-}}$and $Z_{2}$ in one of the labor market clearing conditions, we can solve for the equilibrium skill premium $\omega^{*}$. (Then, at $\omega^{*}$, the other labor market is also cleared.) From $\omega^{*}$ follow factor prices and prices, output levels and employment in the three sectors and the sectoral structure of the economy in a straightforward way.
} 
The calibrated model fits the targets fairly well. Further, the other equilibrium values following from the model are also very similar to the values observed in the CPS data. Hourly wages in our model are $w^{H}=\$ 24.7$ (CPS data: $\$ 25.1$ ), $w^{L}=\$ 16.1$ (CPS: $\$ 15.8$ ) and the resulting prices are $p_{z_{1}}=$ $0.25, p_{z_{2}}=0.2028$ Labor employments (total hours) are $H_{x}=49046 \mathrm{~m}$ (CPS: $49006 \mathrm{~m}), L_{x}=153244 \mathrm{~m}$ (CPS: 153143m), $H_{z_{1}}=2748 \mathrm{~m}$ (CPS: 2785m), $L_{z_{1}}=6085 \mathrm{~m}$ (CPS: 5990m), $H_{z_{2}}=627 \mathrm{~m}(\mathrm{CPS}: 634 \mathrm{~m}), L_{z_{2}}=475 \mathrm{~m}$ (CPS: $466 \mathrm{~m})$. For the skill intensities we get $\kappa_{x}=0.32<\kappa_{z_{1}}=0.45<\kappa_{z_{2}}=1.32$ (corresponding data in CPS: $\kappa_{x}=0.32<\kappa_{z_{1}}=0.45<\kappa_{z_{2}}=1.32$ ), which shows that the two finance sub-sectors are more skill intensive than the rest of the economy. These numbers show that the calibrated model matches the U.S. economy in the period 1980-1994 fairly well.

\subsubsection{Numerical exercises}

We show now how our calibrated model can predict the twofold structural change and the rising wage inequality between period 1980-1994 and period 1995-2009 as seen in Figures 2-4. To do so, we look at the prediction of our calibrated model if shocked by exogenous changes. Thereby, we apply the changes in the exogenous parameters of our model as observed in data. In other words, we use as shocks the average values of $\bar{L}, \bar{H}, h^{L}, h^{H}, \alpha_{x}, \alpha_{z_{1}}$, $\alpha_{z_{1}}, A_{x}, P T_{65}, P T^{65}$, LEratio and $r^{f}$ for the time span 1995-2009 instead of

\footnotetext{
${ }^{28}$ The magnitude of the financial services prices could be interpreted in the following wag: A household has to pay the unit costs of financial intermediation, estimated by Philippon (2015) to be 0.015-0.02, during all his/hers "capital-accumulation" years ( 15-times from 1980-1994 to 1995-2009).
} 
the ones for the time span 1980-199429 In addition, we also consider shocks on the internally calibrated parameter $A_{z_{1}}, A_{z_{2}}, \delta$ and $\mu$.

As a first exercise, we shock the model with ceteris paribus shocks. This means that we apply each of the changes listed in Table 3 separately. For the exogenous parameters we apply observed changes; for the internally calibrated parameters potential changes. The qualitative effects of such ceteris paribus changes on the skill premium $\omega$, on the between sectoral structure $\Psi$ and the within structure $\Phi$ are summarized in Table 3 .

Table 3: Comparative statics

\begin{tabular}{|c|c|c|c|}
\hline & $\omega$ & $\Psi$ & $\Phi$ \\
\hline Uniform productivity progress $A_{j}$ (income effect) & + & + & + \\
\hline$X$-biased technical change $A_{x}$ & + & + & + \\
\hline$Z_{1}$-biased technical change $A_{z_{1}}$ & - & - & - \\
\hline$Z_{2}$-biased technical change $A_{z_{2}}$ & - & - & + \\
\hline Skill-biased technical change $\alpha_{x}, \alpha_{z_{1}}, \alpha_{z_{2}}$ & + & - & - \\
\hline Higher subsistence requirement young $\overline{e_{0}}$ & - & - & - \\
\hline Higher subsistence requirement old $\overline{e_{1}}$ & + & + & - \\
\hline Increased skill supply $k$ & - & - & + \\
\hline Lower safe return $r\left(\frac{\overline{e_{1}}}{r}\right.$-channel $)$ & + & + & - \\
\hline Lower relative return $\rho$ & + & - & + \\
\hline More completeness $\mu$ & + & - & + \\
\hline Fall in $\delta$ & - & - & - \\
\hline
\end{tabular}

Notes: + is a positive comparative static effect. - is a negative comparative static effect.

\footnotetext{
${ }^{29}$ See Table 1 in Appendix D for data of the average values for 1995-2009 of $\bar{L}, \bar{H}, h^{L}$, $h^{H}, \alpha_{x}, \alpha_{z_{1}}, \alpha_{z_{1}}, A_{x}, P T_{65}, P T^{65}$, LEratio and $r^{f}$. For $R$ we use again a constant risk premium of four percentage points.
} 
Uniform productivity progress $A_{j}$ means that the productivities in all three sectors $j \in\left\{X, Z_{1}, Z_{2}\right\}$ grow with the same rate (i.e., $A_{z_{i}}^{1}=g_{x} A_{z_{i}}^{0}$, where $g_{x}=A_{x}^{1} / A_{x}^{0}$ is given by the observed average values of $A_{x}^{0}$ in 1880-1994 and of $A_{x}^{1}$ in 1995-2009). Consistent with Proposition 5-7] such a uniform productivity progress leads to an increase in the skill premium as well as to the twofold structural change. This is due to the income effect arising through the subsistence requirements $\overline{e_{0}}>0$ and $\overline{e_{1}}>0$. Sector-biased technical change means that only the respective sector grows, while the other two productivity levels are kept constant (as growth rate we use always the observable rate $g_{x}$ ). The comparative static effects of such a ceteris paribus shock are a combination of income and substitution effects. (Sector-specific) skill-biased technical change $\alpha_{j}$, as observed in the data for $j \in\left\{X, Z_{1}, Z_{2}\right\}$, induces clearly an increase of the skill premium. Higher subsistence requirements (mainly a higher $\overline{e_{1}}$ because of aging households) lead to similar effects as predicted in Propositions 5, An increase in skill supply $k=\frac{\bar{H} h^{H}}{\bar{L} h^{L}}$ leads to within structural change because there are more high-skilled people who demand more finance sub-sector $Z_{2}$ services. A lower $r$ has the same effect like a higher $\overline{e_{1}}$. Furthermore, a lower relative return $\rho$ (induced by an increase of the risk premium by one percentage point) or more market completeness $\mu$ (by ten percentage points) raise the skill premium and make new financial services relatively more attractive compared to services for deposits. Finally, a fall in $\delta$ to 0.335 , which leads to a lower saving rate close to $18.60 \%$ as observed on average for the time span 1995-2009, induces a decline in the skill premium and leads to smaller financial sectors.

As a second exercise, we shock our calibrated model with simultaneous shocks. This means, we shock our economy by using all the shocks in the 
exogenous parameters together (i.e., new average values of $\bar{H}, \bar{L}, h^{H}, h^{L}, \alpha_{x}$, $\alpha_{z_{1}}, \alpha_{z_{1}}, A_{x}, P T_{65}, P T^{65}$, LEratio and $r^{f}$ for time span 1995-2009). Further, we assume uniform technological progress. This means, the productivities in the $Z$-sectors develop identical to the productivity in the $X$-sector. Discount parameter $\delta$ and completeness measure $\mu$ are held fixed at the calibrated values. With this procedure, we get a quantitative model prediction which can then be compared with the empirical development (see Table 4). Under simultaneous shocks our model predicts a rise in the skill premium $\omega$ from 1.54 to 1.85 and two-fold structural change towards and within finance with a rise of $\Psi$ from $5.14 \%$ to $5.29 \%$ and a rise of $\Phi$ from $13.96 \%$ to $15.27 \%$.

Table 4: Predictions

\begin{tabular}{lccll}
\hline Variables & Model & Data & Source & Description \\
\hline$\omega^{*}$ & 1.85 & 1.85 & CPS & Skill premium \\
$\Psi$ & $5.29 \%$ & $5.53 \%$ & CPS & Between sectoral structure \\
$\Phi$ & $15.27 \%$ & $23.47 \%$ & CPS & Within sectoral structure \\
\hline
\end{tabular}

Notes: $\omega^{*}$ is the equilibrium skill premium (per hour worked). $\Psi$ corresponds to $\frac{p_{z_{1}} D+p_{z_{2}} F}{X}$ in the model and to $\Psi_{\text {normalized }}$ in the data. $\Phi$ corresponds to $\frac{p_{z_{1}} D}{p_{z_{2}} F}$ in the model and to $\Phi_{\text {normalized }}$ in the data.

Comparing the model values with data, we see that the simulated equilibrium values underestimate the between structural change (only a little) and mainly the within structural change. This means, additional shocks are needed to come closer to data values. According to our analysis, possible candidates for such additional shocks (unobserved in our data) are: More market completeness ( $\mu$-shock), biased technical change in the $Z$-sectors (shown in Table 3) or diminished fixed costs in the financial sector and distorted portfolio choices as discussed in Section 7. Overall, the simulated development in our 
calibrated model illustrates the channels that lead to the observed rise in the skill premium and the two-fold structural change towards and within the financial sector fairly well; at least as far as these changes are caused by economic fundamentals. As pointed out in the beginning of this section, the normalized financial sector ratios considered here are amplified in reality by rents.

\section{Conclusion}

The presented $3 \times 3$ model of production and financial services helps to explain the two-fold structural change towards and within the financial sector. The analysis emphasized demand side effects by using quasi-homothetic preferences of the Stone-Geary form and accounted for supply side effects by considering for different skill-intensities in production of goods and financial services. The theoretical analysis was based on established building blocks for modeling a multi-sector economy with production and was at the same time sufficiently tractable to allow analytical results. The comparative-static equilibrium analysis showed the effects of productivity progress and technical change, skill supply, present and future subsistence requirements and financial product innovation on the skill premium and on the sectoral structure of an economy. Both the size of the financial sector relative to the non-financial sector as well as the size of the new finance sector relative to the traditional finance sector were considered. Moreover, in several extensions the robustness of the results was discussed and the effects of rents or distortions in the financial sector were addressed. The main insight of the results from the theoretical analysis can be summarized as follows: If one looks for a sin- 
gle economic source (apart from assuming rents or distortions) that could explain the twofold structural change towards and within finance and the rising skill premium simultaneously, the income effect is a robust candidate. Other channels, like relative price effects within the financial sector lead to more ambiguous results.

The quantitative results derived in the theoretical analysis were illustrated quantitatively by calibrating the model to U.S. data from 1980-1994. The numerical implementation of the model shows that the subsequent development observed in the period 1995-2009 can be explained fairly well. While uniform productivity growth, working through the income effect, is confirmed as a main source of structural change towards and within finance, skill biased technical change is important too for matching the rise in the skill premium.

The paper leaves open two main questions which are important in the current debate about real economic development and financialization. The first open problem is the finance premium. While it is obvious that the rents revealed by the premium contribute to inequality and blow up the structural change towards and withing finance considered in this paper, the question where the premium comes from is less clear. In recent years, several attempts have been made to explain the premium by asymmetric information between shareholders and employees in the banking sector. Yet, this can only explain the redistribution of earnings within the financial sector. Our hypothesis is that it is the asymmetry between financial agents and their clients which allows to extract rents. After all, the financial sector is an expert system to start with. It would be worthwhile to integrate this aspect into the presented framework. Possible channels for modeling the rent-generating information asymmetry would be intransparent cost structures or confusion by financial 
innovation (distorted $\mu$-beliefs).

The second open question left to future research is how structural change towards and within the financial sector affects economic productivity. The literature on financial development and growth has identified market completion by financial innovation as an important source of growth. Does the recent evidence on a negative effect of financial development on economic growth indicate that the huge flood of new financial products since the 1990thies has not really completed markets but rather generated obfuscation? In the framework presented in this paper such obfuscation would induce euphoric beliefs about the degree of market completeness $(\mu)$, which is one of the drivers of structural change within finance and at the same time a possible lever for rent extraction. Another possible channel for a growth dampening effect could be the absorption of high-skilled labor in the finance sector, which leads to scarcity of talent outside the financial sector and may slowdown productivity growth.

To take stocks: The empirical evidence shows that the expansion of the financial sector and the changing structure within the financial sector towards new finance are partly caused by the finance premium. This is a rent which remains unexplained in the presented paper. But there are also economic fundamentals which drive the twofold structural change. These drivers are the focus of the paper. The main explanation for the observed two fold structural change is a rise in average income generated by uniform productivity growth across sectors and factors, which changes demand for financial services, combined with skill-biased technical change that drives up the skill premium. 
Could the structural change towards and within finance, accompanied by a rise in the skill premium, come to a halt? According to our model, apart from a slowdown of growth, the following factor exert downward pressure on finance shares and skill premium: Finance-biased productivity progress, less attractive risky investments, a decline in the saving rate or a stop in the proliferation of new financial products. 


\section{A Portfolio Choice}

Agent index $l$ is skipped in the appendix. If financial intermediaries take exante a fee in the form $T=p_{z_{1}} d+p_{z_{2}}(s-d)$, the expected utility maximization problem is given by:

$\max _{s,\left\{f_{\theta}\right\}_{\theta \in \Theta}, d} \mathbb{E} U=\log \left(e_{0}-\bar{e}_{0}\right)+\delta\left[\mu \sum_{\theta \in \Theta} \pi_{\theta} \log \left(e_{\theta}-\bar{e}_{1}\right)+(1-\mu) \log \left(e_{\bar{\Theta}}-\bar{e}_{1}\right)\right]$ s.t.

$$
\begin{aligned}
& e_{0}+\left(1+p_{z_{2}}\right) s+\left(p_{z_{1}}-p_{z_{2}}\right) d=y, \\
& e_{\theta}=\left\{\begin{array}{l}
R_{\theta} f_{\theta}+r d, \text { if } \theta \in \Theta \\
r d, \text { otherwise }
\end{array}\right. \\
& s=\sum_{\theta \in \Theta} f_{\theta}+d .
\end{aligned}
$$

Denoting by $\lambda$ the Lagrange multiplier for constraint (A.3) the first-order conditions of the households' expected utility maximization problem give:

$$
\begin{aligned}
& \frac{\partial \mathcal{L}}{\partial s}=-\frac{1+p_{z_{2}}}{e_{0}-\bar{e}_{0}}+\lambda=0 \\
& \frac{\partial \mathcal{L}}{\partial f_{\theta}}=\delta \mu \pi_{\theta} \frac{R_{\theta}}{e_{\theta}-\bar{e}_{1}}-\lambda=0 \\
& \frac{\partial \mathcal{L}}{\partial d}=-\frac{p_{z_{1}}-p_{z_{2}}}{e_{0}-\bar{e}_{0}}+\delta\left[\mu \sum_{\theta \in \Theta} \pi_{\theta} \frac{r}{e_{\theta}-\bar{e}_{1}}+(1-\mu) \frac{r}{r d-\bar{e}_{1}}\right]-\lambda=0, \\
& \frac{\partial \mathcal{L}}{\partial \lambda}=s-\sum_{\theta \in \Theta} f_{\theta}-d=0 .
\end{aligned}
$$

Using (A.4), (A.5) and (A.6), we have

$$
d=\frac{\delta(1-\mu)}{\lambda\left(\frac{1+p_{z_{1}}}{1+p_{z_{2}}}-r / R\right)}+\frac{\bar{e}_{1}}{r}
$$


where $R=\pi_{\theta} R_{\theta}$. From (A.2), (A.5) and (A.7), we have

$$
s=\frac{\delta \mu}{\lambda}+(1-r / R) d+\frac{1}{R} \bar{e}_{1} .
$$

In the end we have

$$
\begin{aligned}
d & =\frac{\delta(1-\mu)}{(1+\delta) P}\left(y-\bar{e}_{0}\right)+\frac{(1+\mu \delta)\left(1+p_{z_{1}}\right)-(1+\delta)\left(1+p_{z_{2}}\right) r / R}{r(1+\delta) P} \bar{e}_{1} \\
& =\frac{1-\mu}{1-p \rho} \frac{\delta}{1+\delta} \frac{y-\bar{y}}{1+p_{z_{1}}}+\frac{\bar{e}_{1}}{r}
\end{aligned}
$$

where $P \equiv\left(1+p_{z_{1}}\right)(1-p \rho), p \equiv \frac{1+p_{z_{2}}}{1+p_{z_{1}}}, \rho \equiv \frac{r}{R}$ and $\bar{y} \equiv \bar{e}_{0}+\frac{\bar{e}_{1}\left(1+p_{z_{1}}\right)}{r}$.

Combining (A.10) with (A.8) and solving for $\lambda$, we obtain

$$
\frac{1}{\lambda}=\frac{y-\bar{y}}{(1+\delta)\left(1+p_{z_{2}}\right)}
$$

Using this and (A.10) in (A.9), we have

$$
\begin{aligned}
s & =\frac{\delta}{(1+\delta)} \frac{y-\bar{y}}{1+p_{z_{2}}}\left[\mu+(1-\rho) \frac{p(1-\mu)}{1-p \rho}\right]+(1-\rho) \frac{\bar{e}_{1}}{r}+\frac{\bar{e}_{1}}{R} \\
& =\frac{\delta}{1+\delta} \frac{y-\bar{y}}{1+p_{z_{2}}} \frac{\mu-p \rho+p(1-\mu)}{1-p \rho}+\frac{\bar{e}_{1}}{r},
\end{aligned}
$$

which can be rewritten in the form

$$
s=\frac{\delta}{1+\delta} \frac{y-\bar{y}}{1+p_{z_{2}}}\left[1+\frac{\left(p_{z_{2}}-p_{z_{1}}\right)(1-\mu)}{\left(1+p_{z_{1}}\right)(1-p \rho)}\right]+\frac{\bar{e}_{1}}{r},
$$

where $p-1=\frac{p_{z_{2}}-p_{z_{1}}}{1+p_{z_{1}}}$ has been used.

Finally, (A.7), A.10) and (A.11) give us

$$
f \equiv \sum_{\theta \in \Theta} f_{\theta}=\frac{\mu-p \rho}{1-p \rho} \frac{\delta}{1+\delta} \frac{y-\bar{y}}{1+p_{z_{2}}}
$$

and from A.1 we conclude

$$
\begin{aligned}
y-e_{0} & =\left(1+p_{z_{1}}\right) d+\left(1+p_{z_{2}}\right) f \\
& =\frac{\delta}{1+\delta}(y-\bar{y})+\frac{\left(1+p_{z_{1}}\right) \bar{e}_{1}}{r} .
\end{aligned}
$$


For the allocation of $f$ on $f_{\theta}, \theta \in \Theta$, we combine (A.2) with (A.5) to get

$$
\begin{aligned}
f_{\theta} & =\pi_{\theta}\left[\frac{\delta \mu}{\lambda}+\frac{\overline{e_{1}}-r d}{R}\right] \\
& =\pi_{\theta} \frac{\delta}{1+\delta} \frac{y-\bar{y}}{1+p_{z_{2}}}\left[\mu-\rho \frac{1-\mu}{1-p \rho} p\right]=\pi_{\theta} f,
\end{aligned}
$$

where (A.10) and $(*)$ have been used for the second equation.

\section{B Corner solutions for securities demand}

To account for the non-negativity constraint $f_{\theta} \geq 0$ we have to add $\sum_{\theta \in \Theta} \psi_{\theta} f_{\theta}$ to the Lagrange function for $\max \mathrm{EU}-$ with $\psi_{\theta} \geq 0$ denoting the Lagrange multiplier for $f_{\theta} \geq 0$. Then, the first order condition for $f_{\theta}$ changes to

$$
\delta \mu \pi_{\theta} \frac{R_{\theta}}{e_{\theta}-\bar{e}_{1}}-\lambda+\psi_{\theta}=0
$$

with $\psi_{\theta} f_{\theta} \leq 0$.

Suppose that $f_{\theta}=0$ for all $\theta$. Then $s=d$ and

$$
\begin{aligned}
& e_{0}-\bar{e}_{0}=y-\bar{e}_{0}-\left(1+p_{z_{1}}\right) d \\
& e_{\theta}-\bar{e}_{1}=r d-\bar{e}_{1}
\end{aligned}
$$

and the first-order conditions

$$
\begin{aligned}
& \text { (s) } \lambda=\frac{1+p_{z_{2}}}{e_{0}-\bar{e}_{0}} \\
& \text { (d) } \quad \delta\left[\mu \sum_{\theta \in S} \pi_{\theta} \frac{r}{e_{\theta}-\bar{e}_{1}}+(1-\mu) \frac{r}{r d-\bar{e}_{1}}\right]=\lambda+\frac{p_{z_{1}}-p_{z_{2}}}{e_{0}-\bar{e}_{0}}
\end{aligned}
$$

reduce to

$$
\delta \frac{r}{r d-\bar{e}_{1}}=\frac{1+p_{z_{1}}}{e_{0}-\bar{e}_{0}}
$$


With (B.2) this solves to

$$
d=\frac{1}{1+\delta}\left[\frac{\delta\left(y-\bar{e}_{0}\right)}{1+p_{z_{1}}}+\frac{\bar{e}_{1}}{r}\right] .
$$

Substituting the solution into (B.2) gives us

$$
\begin{aligned}
& e_{0}-\bar{e}_{0}=\frac{1}{1+\delta}\left[y-\bar{e}_{0}-\frac{\left(1+p_{z_{1}}\right) \bar{e}_{1}}{r}\right] \\
& e_{\theta}-\bar{e}_{1}=\frac{\delta r}{(1+\delta)}\left[\frac{y-\bar{e}_{0}}{1+p_{z_{1}}}-\frac{\bar{e}_{1}}{r}\right] .
\end{aligned}
$$

Using this in (B.1) we obtain: $\psi_{\theta} \geq 0$ if and only if

$$
\mu \pi_{\theta} R_{\theta} \leq \frac{1+p_{z_{2}}}{1+p_{z_{1}}} r
$$

where $\lambda=\frac{1+p_{z_{2}}}{e_{0}-\bar{e}_{0}}$ has been used from (B.3).

Since $\pi_{\theta} R_{\theta}=R,(\bar{B} .6)$ reduces to

$$
\frac{1+p_{z_{1}}}{1+p_{z_{2}}} \mu R \leq r
$$

which is equivalent to $R \mu\left(1+p_{z_{1}}\right) \leq\left(1+p_{z_{2}}\right) r$.

Hence non-negativity $f_{\theta}>0, \theta \in \Theta$, requires

$$
R \mu\left(1+p_{z_{1}}\right)>\left(1+p_{z_{2}}\right) r
$$

\section{Further proofs}

Proof of Fact 3. With (11) and (12) the condition $y^{L}=b_{L} w_{L}>\bar{y}=\bar{e}_{0}+$ $\frac{\left(1+p_{z}\right) \bar{e}_{1}}{r}$ takes the form

$$
A_{x} \Gamma_{x} \omega^{-\alpha_{x}}\left[b_{L}-\frac{\bar{e}_{1}}{r A_{z_{1}} \Gamma_{z_{1}}} \omega^{\alpha_{z_{1}}}\right]>\bar{e}_{0}+\frac{\bar{e}_{1}}{r} .
$$


The left side of the equation declines in $\omega$. Thus $y^{L}>\bar{y}$ requires

$$
\omega<\omega_{L}^{+}\left(\begin{array}{c}
A_{x}, A_{z_{1}}, b_{L}, \bar{e}_{0}, \frac{\bar{e}_{1}}{r} \\
++{ }_{+}
\end{array}\right),
$$

where $\omega_{L}^{+}$is determined by the equation:

$$
b_{L}=\left(\bar{e}_{0}+\frac{\bar{e}_{1}}{r}\right) \frac{\omega^{\alpha_{x}}}{A_{x} \Gamma_{x}}+\frac{\bar{e}_{1}}{r} \frac{\omega^{\alpha_{z_{1}}}}{A_{z_{1}} \Gamma_{z_{1}}} .
$$

Proof of Lemma 1, a) Let $B_{1} \equiv A_{x} \Gamma_{x} \frac{b_{L} \bar{L}}{N}$ and $B_{2} \equiv \frac{A_{x} \Gamma_{x}}{A_{z} \Gamma_{z}}$. Using (26) and (12), we have

$$
\bar{w}=B_{1} \omega^{-\alpha_{x}}(1+\omega k), \quad p_{z}=B_{2} \omega^{\alpha_{z}-\alpha_{x}}
$$

Then $\bar{\eta}$ can be reformulated as

$$
\bar{\eta}=\frac{\bar{w}-\bar{y}}{1+p_{z}}=\frac{B_{1} \omega^{-\alpha_{x}}(1+\omega k)-\overline{e_{0}}}{1+B_{2} \omega^{\alpha_{z}-\alpha_{x}}}-\frac{\overline{e_{1}}}{r},
$$

where (18) is used to substitute $\bar{y}$.

To get the shape of $\bar{\eta}$, first notice that

$$
\operatorname{sign} \frac{\partial \bar{\eta}(\omega)}{\partial \omega}=\operatorname{sign} \frac{\partial G(\omega)}{\partial \omega},
$$

where $G(\omega) \equiv \frac{B_{1}(1+\omega k)-\overline{e_{0}} \omega^{\alpha_{x}}}{\omega^{\alpha x}+B_{2} \omega^{\alpha z}}$. Differentiating $G(\omega)$ we have

$$
\frac{\partial G(\omega)}{\partial \omega}=\frac{\mathcal{L}(\omega)}{\left(\omega^{\alpha_{x}}+B_{2} \omega^{\alpha_{z}}\right)^{2}},
$$

where

$$
\begin{aligned}
\mathcal{L}(\omega)= & B_{1} \omega^{\alpha_{x}}\left[k\left(1-\alpha_{x}\right)-\frac{\alpha_{x}}{\omega}\right]+B_{1} B_{2} \omega^{\alpha_{z}}\left[k\left(1-\alpha_{z}\right)-\frac{\alpha_{z}}{\omega}\right] \\
& +\overline{e_{0}} B_{2}\left(\alpha_{z}-\alpha_{x}\right) \omega^{\alpha_{x}+\alpha_{z}-1}
\end{aligned}
$$


We have $\frac{\partial G(\omega)}{\partial \omega}>0$ if and only if $\mathcal{L}(\omega)>0$. For $\alpha_{x}+\alpha_{z}>1, \mathcal{L}(\omega)$ is an increasing function in $\omega$. Moreover,

$$
\lim _{\omega \rightarrow 0^{+}} \mathcal{L}=-\infty, \quad \lim _{\omega \rightarrow+\infty} \mathcal{L}=+\infty
$$

Therefore, there exists a unique $\underline{\omega}$ with $\mathcal{L}(\underline{\omega})=0$ and: $\frac{\partial \bar{\eta}(\omega)}{\partial \omega} \gtreqless 0$ if and only if $\omega \gtreqless \underline{\omega}$. A rise in $k$ or $\bar{e}_{0}$ shifts $\mathcal{L}(\omega)$ upward so that $\underline{\omega}$ declines. The impacts of $B_{1}, B_{2}$ (and thus of $A_{x}, A_{z}, \frac{b_{L} \bar{L}}{N}$ ) on $\underline{\omega}$ are ambiguous because $\kappa_{x}<k<\kappa_{z}$ imply $k\left(1-\alpha_{x}\right)-\frac{\alpha_{x}}{\omega}>0$ and $k\left(1-\alpha_{z}\right)-\frac{\alpha_{z}}{\omega}<0$.

b) We have

$$
\bar{\eta}=\frac{A_{x} \Gamma_{x} \frac{b_{L} \bar{L}}{N} \omega^{-\alpha_{x}}(1+\omega k)-\overline{e_{0}}}{1+\frac{A_{x} \Gamma_{x}}{A_{z} \Gamma_{z}} \omega^{\alpha_{z}-\alpha_{x}}}-\frac{\overline{e_{1}}}{r} .
$$

By eye inspection we get:

$$
\bar{\eta}\left(\omega \mid \begin{array}{c}
A_{x}, A_{+}, \underset{+}{k}, \frac{b_{L} \bar{L}}{N}, \overline{e_{0}}, \frac{\overline{e_{1}}}{r} \\
+
\end{array}\right)
$$

Proof of Fact 6. According to (38), $Z^{S}=A_{z} b_{L} \bar{L} \frac{\gamma_{z}^{\alpha}}{\gamma_{z}-\gamma_{x}} \omega^{-\alpha_{z}}\left(k \omega-\gamma_{x}\right)$, where $\kappa_{j}=\frac{\gamma_{j}}{\omega}$ has been used from (9).

We have $\frac{\partial \omega^{-\alpha_{z}}\left(k \omega-\gamma_{x}\right)}{\partial \omega}=\omega^{-\alpha_{z}}\left[\left(1-\alpha_{z}\right) k+\frac{\alpha_{z} \gamma_{x}}{\omega}\right]$. This term is positive and decreasing in $\omega$. 


\section{Data}

Table 5: Parameters 1995-2009

\begin{tabular}{lcll}
\hline Parameter & Data & Source & Description \\
\hline $\bar{L}$ & $109 \mathrm{~m}$ & CPS & \# Low-skilled employees \\
$\bar{H}$ & $41.2 \mathrm{~m}$ & CPS & \# High-skilled employees \\
$h^{L}$ & 1757.7 & CPS & Yearly hours of low-skilled \\
$h^{H}$ & 2027.5 & CPS & Yearly hours of high-skilled \\
$\alpha_{x}$ & 0.44 & CPS & Output ela. of high-skilled in $X$ \\
$\alpha_{z_{1}}$ & 0.54 & CPS & Output ela. of high-skilled in $Z_{1}$ \\
$\alpha_{z_{2}}$ & 0.79 & CPS & Output ela. of high-skilled in $Z_{2}$ \\
$A_{x}$ & 44.66 & CPS & Technology level in $X$ \\
$P T_{65}$ & $\$ 15,816$ & U.S. Dep. of commerce & Real poverty threshold $<65$ \\
$P T^{65}$ & $\$ 14,217$ & U.S. Dep. of commerce & Real poverty threshold $>65$ \\
$L E r a t i o$ & 3.77 & LE from World Bank & Old-age ratio \\
$r^{f}$ & 0.82 & St.Louis Fed & Real Feds fund rate \\
\hline$A_{z_{1}}$ & 190.56 & Model calibration $+A_{x}$-growth & Technology level in $Z_{1}$ \\
$A_{z_{2}}$ & 257.06 & Model calibration $+A_{x}$-growth & Technology level in $Z_{2}$ \\
$\delta$ & 0.375 & Model calibration & Discount rate \\
$\mu$ & 0.750 & Model calibration & Certainty measure \\
\hline
\end{tabular}

Notes: The figures are the averaged values for the time range $t=1995-2009$ of: $\alpha_{j, t}=\frac{\kappa_{j, t} \omega_{j, t}}{1+\kappa_{j, t} \omega_{j, t}}$ with $\kappa_{j, t}=\frac{h_{j, t}^{H} \bar{H}_{j, t}}{h_{j, t}^{L} L_{j, t}}$ and $\omega_{j, t}=\frac{w_{j, t}^{H}}{w_{j, t}^{L}}, j \in\left\{x, z_{1}, z_{2}\right\}, h_{t}^{H}=h_{x, t}^{H}$ and $h_{t}^{L}=h_{x, t}^{L} . \quad A_{x, t}=\frac{w_{x, t}^{L}}{\Gamma_{x, t} \omega_{x, t}^{-\alpha_{x, t}}}$ with $\Gamma_{x, t}=\alpha_{x, t}{ }^{\alpha_{x, t}}\left(1-\alpha_{x, t}\right)^{1-\alpha_{x, t}} . \quad P T$ is the real poverty threshold of a two-people household (nominal values are adjusted by CPI-URS-inflation) with $P T_{65}$ denoting the relevant value for households younger than 65 and $P T^{65}$ denoting the value relevant for older ones. LEratio is the ratio of workingtime to retirement: $(65-20) /(L E-65)$, where $L E$ denotes life expectancy; 65 is the retirement age and 20 is the assumed start of the working-life. $r^{f}$ is the real Feds fund rate (Feds fund rate minus CPI-U-RS-inflation). CPI-U-RS-inflation data from U.S. Dep. of labor. 


\section{References}

Acemoglu, D. (2002). Directed technical change. Review of Economic Studies 69(4), 781-809.

Acemoglu, D. and F. Zilibotti (1997). Was Promotheus unbound by chance? Risk, diversification, and growth. Journal of Political Economy 105(4), 709-751.

Achury, C., S. Hubar, and C. Koulovatianos (2012). Saving rates and portfolio choice with subsistence consumption. Review of Economic Dynamics 15(1), 108-126.

Atkinson, A. B. (1997). Bringing income distribution in from the cold. The Economic Journal 107(441), 297-321.

Beck, T., B. Büyükkarabacak, F. K. Rioja, and N. T. Valev (2012). Who Gets the Credit? And Does It Matter? Household vs. Firm Lending Across Countries. The B.E. Journal of Macroeconomics 12(1), 1-44. Article 2.

Boppart, T. (2014). Structural change and the Kaldor facts in a growth model with relative price effects and non-Gorman preferences. Econometrica 107(441), 297-321.

Boppart, T. (2015). To which extent is the rise in the skill premium explained by an income effect? mimeo.

Capelle-Blancard, G. and C. Labonne (2011). More Bankers, More Growth? Evidence from OECD Countries. CEPII Document de Travail 2011-22.

Cecchetti, S. G. and E. Kharroubi (2015). Why does financial sector growth crowd out real economic growth? BIS Working Papers 490.

Célérier, C. and B. Vallée (2014). The motives for financial complexity: An empirical investigation. mimeo. 
Célérier, C. and B. Vallée (2015). Returns to talent and the finance wage premium. mimeo.

Falkinger, J. (2014). In search of economic reality under the veil of financial market. Working paper series / Department of Economics 154.

Föllmi, R. and J. Zweimüller (2008). Structural change, Engel's consumption cycles and Kaldor's facts of economic growth. Journal of Monetary Economics 55(7), 1317-1328.

Gennaioli, N., A. Shleifer, and R. W. Vishny (2014). Finance and the preservation of wealth. Quarterly Journal of Economics 129(3), 1221-1254.

Greenwood, J. and B. Jovanovic (1990). Financial development, growth, and the distribution of income. Journal of Political Economy 98(5), 1076-1107.

Greenwood, J. and D. Scharfstein (2013). The growth of finance. Journal of Economic Perspectives 27(2), 3-28.

Gründler, K. and J. Weitzel (2012). The financial sector and economic growth in a panel of countries. Wirtschaftswissenschaftliche Beiträge des Lehrstuhls für Volkswirtschaftslehre, insbes. Wirtschaftsordnung und Sozialpolitik, Universität Würzburg 123.

Kneer, C. (2013, September). The absorption of talent into finance: Evidence from u.s. banking deregulation. DNB Working Paper 391.

Law, S. H. and N. Singh (2014). Does too much finance harm economic growth. Journal of Banking and Finance 41, 36-44.

Levine, R. (2005). Finance and growth: Theory and evidence. Handbook of Economic Growth 1A, 855-934.

Machin, S. and J. Van Reenen (1998). Technology and changes in skill structure: Evidence from seven OECD countries. The Quarterly Journal of Economics 113(4), 1215-1244. 
Philippon, T. (2014). Notes on equilibrium financial intermediation. mimeo.

Philippon, T. (2015). Has the US finance industry become less efficient? on the theory and measurement of financial intermediation. The American Economic Review 105(4), 1408-1438.

Philippon, T. and A. Reshef (2007). Skill biased financial development: Education, wages and occupations in the U.S. financial sector. NBER Working Paper 13437.

Philippon, T. and A. Reshef (2012). Wages and human capital in the U.S. financial industry: 1909-2006. Quaterly Journal of Economics 127(4), 1551-1609.

Philippon, T. and A. Reshef (2013). An international look at the growth of modern finance. Journal of Economic Perspectives 27(2), 73-96.

Piketty, T. (2014). Capital in the twenty-first century. Cambridge, Mass.: The Belknap Press of Harvard University Press.

Piketty, T. and E. Saez (2003). Income inequality in the United States, 1913-1998. Quarterly Journal of Economics 118(1), 1-39.

Rousseau, P. L. and P. Wachtel (2011). What is happening to the impact of financial deepening on economic growth? Economic Inquiry 49(1), 276-288.

Studer, S. (2015). An equilibrium model with diversification-seeking households, competing banks and (non-)correlated financial innovations. mimeo.

Suellow, T. (2015). The skill-intensity of financial service consumption: An input-output analysis. mimeo. 